\title{
Pyrolysis S2-peak characteristics of Raniganj shales (India) reflect complex combinations of kerogen kinetics and other processes related to different levels of thermal maturity
}

\author{
David A. Wood ${ }^{1 *}$, Bodhisatwa Hazra ${ }^{2}$ \\ ${ }^{1}$ DWA Energy Limited, Lincoln, United Kingdom \\ ${ }^{2}$ Coal Petrology Section, Resource Quality Assessment Division, CSIR-Central Institute of Mining and Fuel Research, \\ Digwadih Campus, Dhanbad, India
}

(Received July 4, 2018; revised July 24, 2018; accepted July 25, 2018; available online August 1, 2018)

\section{Citation:}

Wood, D.A., Hazra, B. Pyrolysis S2-peak characteristics of raniganj shales (India) reflect complex combinations of kerogen kinetics and other processes related to different levels of thermal maturity. Advances in Geo-Energy Research, 2018, 2(4): 343-368, doi:

10.26804/ager.2018.04.01.

Corresponding author:

*E-mail: dw@dwasolutions.com

Keywords:

Kerogen kinetics from pyrolysis gas-prone shales India

Rock-Eval variable heating rates shale kinetic/physical properties S2-peak-shape characterization

\begin{abstract}
:
The Permian shales of the Raniganj basin, India, have experienced a dramatic burial history of rapid subsidence (Jurassic-Early Cretaceous) followed by igneous intrusion (Cretaceous) and rapid uplift and erosion (Late Cretaceous-Tertiary). This has left these shales with mixed kerogen macerals with a characteristic thermal signature, ranging from early mature to post mature, which is reflected in the characteristics of their pyrolysis S2 peak. Many of these shales are today at peak thermal maturity but reached that condition more than 100 million years ago. They have significant potential to be exploited as a shale gas resource and their S2 peak characteristics should help to identify sweet spots for such exploitation. Here we analyze single-rate and multi-rate heating ramp Rock-Eval data from a suite of these shales at varying stages of thermal maturity. The S2 peak shapes provide significant insight to the kerogen kinetics involved in their thermal evolution. However, detailed fitting of the peak shapes with kerogen-kinetic mixing models indicate that factors other than static firstorder reaction kinetics are also involved in their S2-peak-shape characteristics. Such factors likely include the catalytic effects, influenced by sulfur and charcoal, on some kerogen components, and kerogen pore-size distribution changes during their complex burial and thermal maturation histories. It is likely that the peak-mature shales contain significant, already generated, gas trapped within some of the kerogen nanopores that may be released during the $\mathrm{S} 2$ pyrolysis heating ramp rather than during the $\mathrm{S} 1$ heating ramp. This causes the $S 2$ peak to broaden in the mature shales, a characteristic that could be used as an exploration marker for zones best suited to shale gas exploitation.
\end{abstract}

\section{Introduction}

Organic-matter-rich shales earlier looked upon as only source rocks, in recent years have gained considerable attention due to their development over the past decade or so as reservoir rocks for many shale gas/oil plays (Passey et al., 2010; Jarvie, 2012a, 2012b). Initial geochemical screening of organic-rich shales, involves the assessment of the quantity, quality, and maturity of the organic-matter, original sourcerock potential, their generation capacity, degree of thermal maturity (Tissot and Welte, 1985; Jarvie, 2012a, 2012b; CarvajalOrtiz and Gentzis, 2015; Chen et al., 2016; Hazra et al., 2017). Moreover, kerogen kinetics information for constructing thermal maturation and petroleum generation models, has emerged as a crucial step in delineating "sweet-spots" of prospectivity across conventional and unconventional oil and gas resource regions (Espitalié et al., 1980; Wood, 1988). The organic geochemical particulars of the kerogen also offer important insight to the hydrocarbon generation process, assisting in the delineation of the stage of catagenesis reached, and the remaining potential for petroleum generation from partially mature kerogen (Wood and Hazra, 2017a, 2017b).

The Rock-Eval pyrolysis technique is widely used as a geochemical screener because it gives valuable information about the kerogen transformation process (S2 peak) and petroleum present in an already generated and moveable state (S1 peak) (Espitalié et al., 1980; Lafargue et al., 1998; Behar et al., 2001). Although, the Rock-Eval technique provides quick, easy and cost-effective analysis that can be readily interpreted, it is clear that in detail the petroleum transformation of shales varies greatly due to their kerogen type, level of thermal 


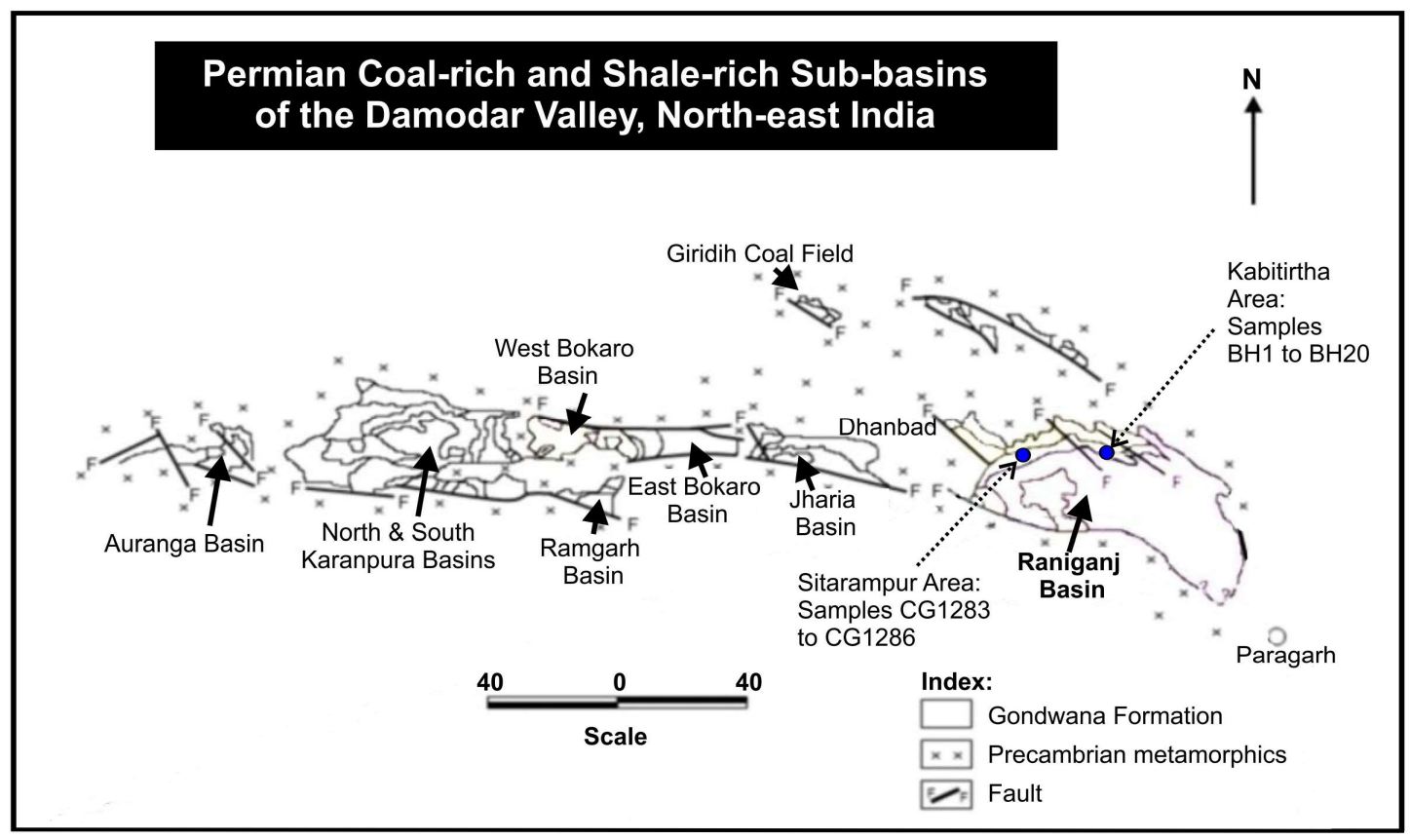

Fig. 1. Regional location map showing sample locations within the Raniganj basin in the context of surrounding Permian gas-prone coal and shale basins of northeast India.

maturity already reached, burial history and other non-organic minerals present. The influence of kerogen kinetics and, in some cases, other non-kinetic factors on Rock-Eval data and the form of the S2 peak, in particular, is significant. However, typically relative little information associated with that S2 peak is used in detailed shale characterization, beyond Tmax, hydrogen index and productivity index. We believe that a significant amount of valuable information is being neglected. A rigorous petroleum-generation model related to the specific kerogen kinetics of an organic-rich shale formation can facilitate more precise interpretations of regional petroleum generation potential and prospectivity (Chen et al., 2016; Wood, 2018a). However, it is difficult to achieve this due to the mixed-kerogen-maceral nature of many shales and the nonkinetic processes involved.

Following its success and rapid development in North America, the shale gas 'game-changer' has by now been evaluated in most prospective regions around the world, and is beginning to be exploited in earnest, including in India. There are huge potential benefits for India to develop its shale gas resources, including the impact that it could have on India's energy supply mix. Several prospective and exploitable petroleum-bearing shale basins exist in India (Sain et al., 2014), with technically recoverable gas-shale resources of approximately 63 TCF (EIA, 2012).

The Raniganj basin, a sub-basin of Damodar Valley basin, was the birthplace of the Indian coal industry, and its potential for shale-gas extraction is already well documented (Sain et al., 2014; Varma et al., 2015a). Previous works have described the organic matter richness, petrographic charac- teristics, mineralogy, high-pressure methane gas adsorption, matrix petroleum-retention properties, biomarkers, and organic geochemistry of this and other Indian Permian shale basins (Mani et al., 2014; Varma et al., 2014a, 2014b, 2014c, 2014d, 2015a, 2015b; Boruah and Ganapathi, 2015a, 2015b; Hazra et al., 2015, 2016, 2018a, 2018b; Tewari et al., 2016; Mendhe et al., 2017, 2018). In this work, for the first time, Rock-Eval data for a range of shales with a wide-range of maturities is used to consider the kerogen kinetics of Permian shales from the Raniganj basin. Moreover, the pyrolysis S2-peak shapes are used to better characterization these shales at different levels of thermal maturity and provide insight to their evolution and petroleum potential.

\section{Raniganj basin setting and sample selection}

The Raniganj basin is one of the Permian coal- and shalebearing basins of the Damodar Valley of Northeast India (Fig. 1).

Samples CG 1283, CG 1284, CG 1285, and CG 1286 were collected from a single exploratory borehole drilled in Sitarampur area of Raniganj basin (Figs. 1 and 2). These samples were selected from a larger set of samples earlier studied and characterized by Varma et al. (2014a, 2014b) and Hazra et al. (2015). The Lower Permian Barakar Formation shales from the Sitarampur area are slightly more mature than shales studied from other areas of the basin, which possibly is caused due to the local impacts of several igneous intrusives in that area (Varma et al., 2014a, 2014b; Hazra et al., 2015). To improve understanding concerning petroleum generation 

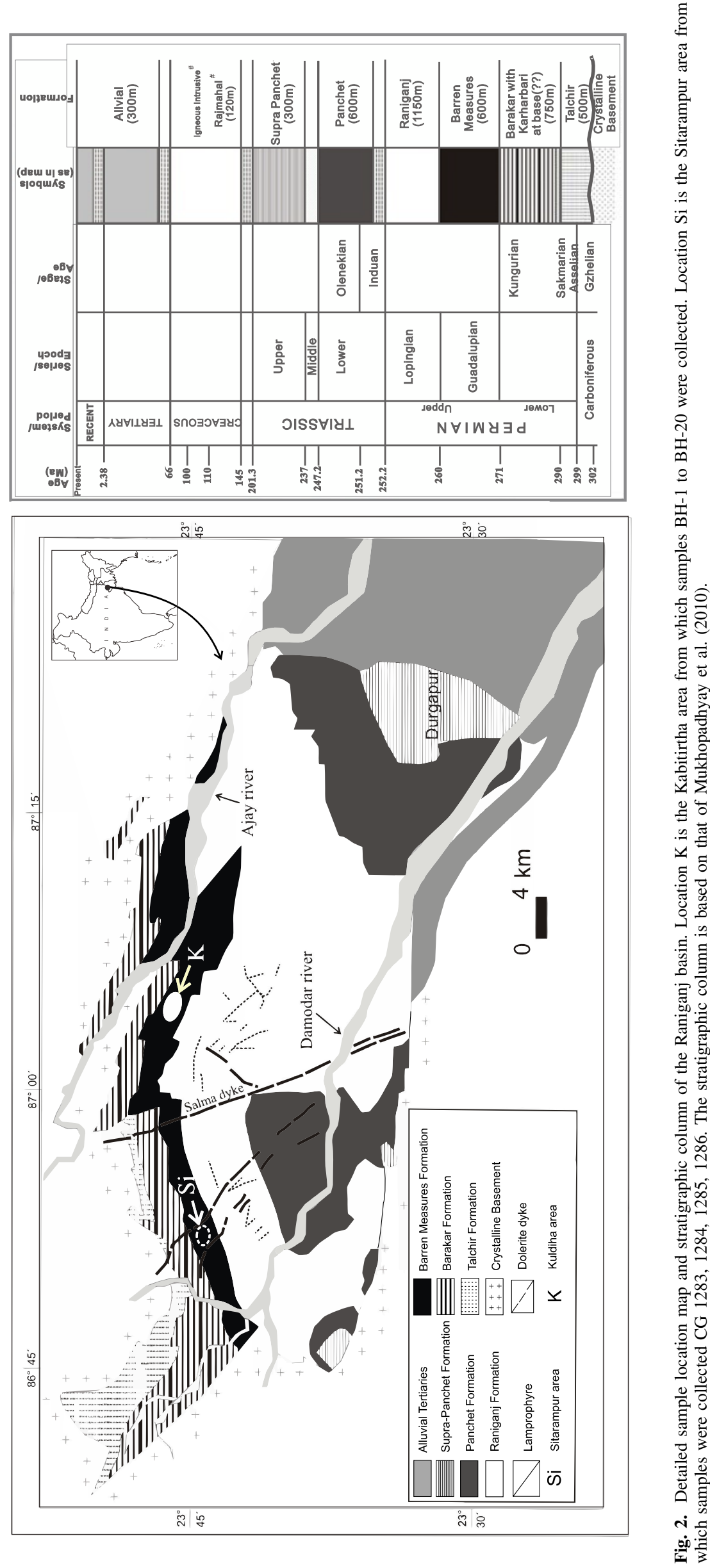
Table 1. Comparative depths and stratigraphic positions of 24 Permian Shale samples from the Raniganj basin, India.

\begin{tabular}{|c|c|c|c|}
\hline \multicolumn{4}{|c|}{ Shale samples analysed by Rock-Eval from the Raniganj basin, India } \\
\hline Sample \# & Formation & Depth (m) & Comments \\
\hline BH-1 & \multirow{20}{*}{$\begin{array}{l}\text { Barakar Formation in the } \\
\text { Kabitirtha area }\end{array}$} & $440-441$ & \multirow{20}{*}{$\begin{array}{l}\text { Located in between coal seams } \\
\text { Salanpur A and B; } \\
\text { Stratigraphically younger than } \\
\text { samples CG } 1283-\text { CG } 1286\end{array}$} \\
\hline $\mathrm{BH}-2$ & & $443-444$ & \\
\hline $\mathrm{BH}-3$ & & $446-447$ & \\
\hline BH-4 & & $453-454$ & \\
\hline BH-5 & & $455-456$ & \\
\hline BH-6 & & $458-459$ & \\
\hline BH-7 & & $461-462$ & \\
\hline $\mathrm{BH}-8$ & & $463-464$ & \\
\hline BH-9 & & $464-465$ & \\
\hline BH-10 & & $467-468$ & \\
\hline BH-11 & & $469-470$ & \\
\hline BH-12 & & $473-474$ & \\
\hline BH-13 & & $478-479$ & \\
\hline $\mathrm{BH}-14$ & & $482-483$ & \\
\hline BH-15 & & $484-484.5$ & \\
\hline BH-16 & & $484.90-485.5$ & \\
\hline BH-17 & & $487-488$ & \\
\hline ВН-18 & & $492-493$ & \\
\hline BH-19 & & $494-495$ & \\
\hline BH-20 & & $497-498$ & \\
\hline CG 1283 & \multirow{4}{*}{$\begin{array}{l}\text { Barakar Formation; } \\
\text { Sitarampur area }\end{array}$} & 678 & \multirow{4}{*}{$\begin{array}{l}\text { Located below coal seam } \\
\text { Salanpur C; these samples are } \\
\text { stratigraphically older than } \\
\text { samples BH-1 to BH- } 20\end{array}$} \\
\hline CG 1284 & & 714 & \\
\hline CG 1285 & & 726 & \\
\hline CG 1286 & & 749 & \\
\hline
\end{tabular}

and the mixed-kerogen-maceral kinetics involved in these Permian shales, samples from Sitarampur were analyzed using a multiple-heating pyrolysis program, beyond the conventional Rock-Eval source-rock analysis cycle.

The samples BH-1 to BH-20 were collected from a single exploratory borehole drilled at Kabitirtha area of the Raniganj basin (Figs. 1 and 2). The single-heating rate pyrograms available for these samples are used to establish what the S2peak shapes from the pyrograms can reveal about the kerogen kinetics, thermal evolution and petroleum generation and expulsion from these shales. The shales from the Kabitirtha area cover a range of thermal maturities, which makes them useful to compare with those more mature samples from the Sitarampur area.

Relative depths and stratigraphic positions of the samples in the two areas described are listed in Table 1.

\section{Burial history of the Raniganj basin}

The Permian coal and shale basins of the Damodar Valley have evolved through a dramatic history of burial and uplift that has resulted in thick accumulations of primarily gas prone organic rich shales of the Barakar and Barren Formations (Sain et al., 2014). The Damodar Valley basins were originally part of one Late Paleozoic Gondwana extensional basin, but what is preserved today are a series of isolated Permo-Triassic sedimentary pockets (Robinson, 1970; Veevers and Tewari, 1995), which were presumably the deeper sub-basins of that original Gondwana basin. The Raniganj basin is one of these sub-basins exposed as its original Mesozoic overburden was progressively eroded and stripped away during uplift that occurred since the Late Cretaceous during the Cenozoic AlpineHimalayan orogeny. This extensive erosion poses the challenge of establishing how deeply buried were the Permian organicrich shales and, with the prevailing geothermal gradients, when those shales originally reach peak thermal maturity.

Patel et al. (2014) conducted a fission-track analysis of apatites extracted from the Raniganj and Panchet (Upper Permian) Formations of the Raniganj basin. This has made it possible to approximate the basin's thermal and burial history, including that of the Barakar Formation (Lower Permian) (Fig. 3). This analysis suggests that the Raniganj Formation was buried to as much as 3,000 metres during the Jurassic. The 


\section{Approximate Thermal \& Burial History of the Raniganj Basin}

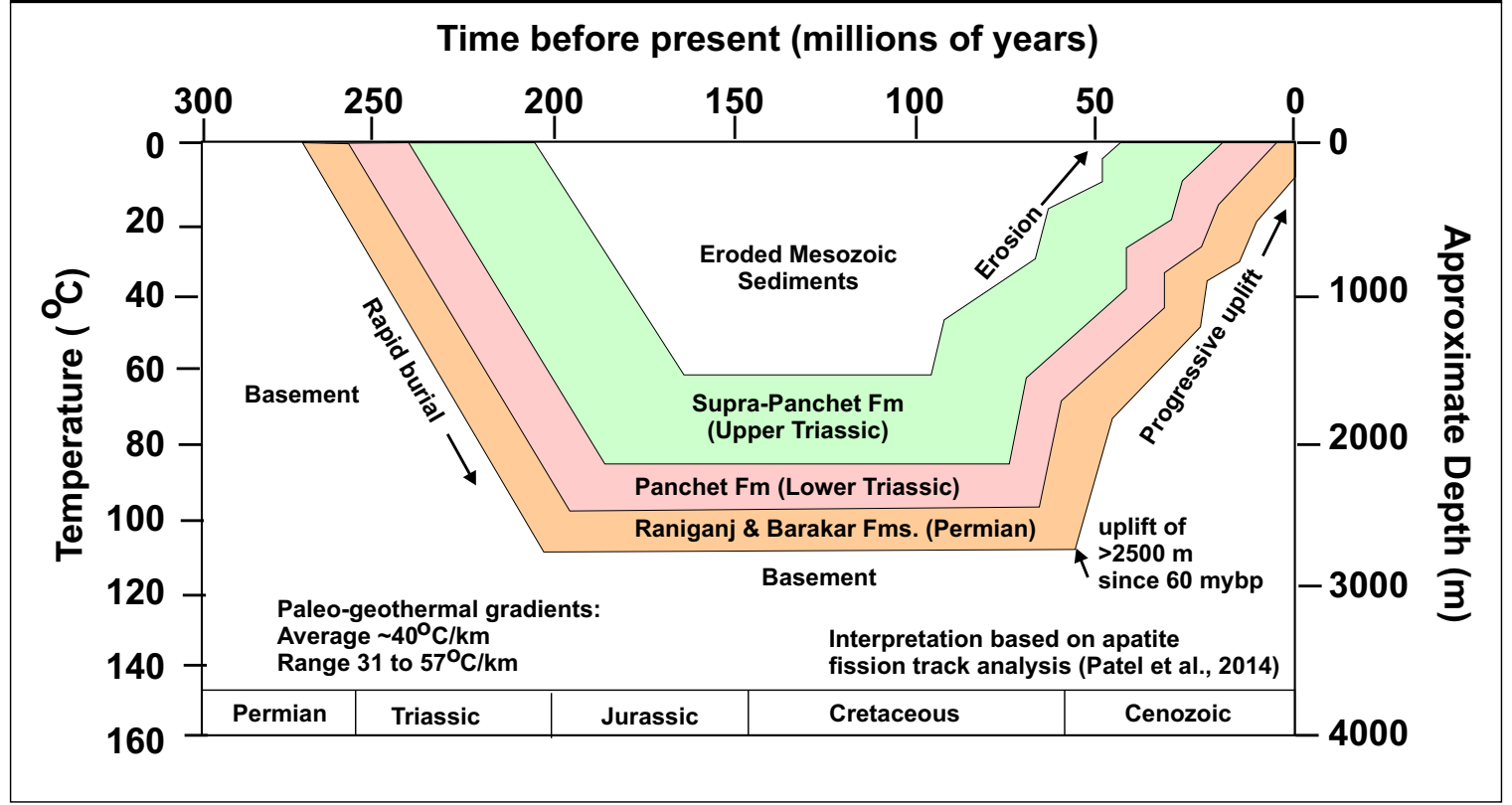

Fig. 3. Schematic thermal and burial history of the Permian formations for the deepest parts of the Raniganj basin.

geothermal gradients of Domador Valley basins is reported to range from $31{ }^{\circ} \mathrm{C} / \mathrm{km}$ to $57{ }^{\circ} \mathrm{C} / \mathrm{km}$ with an average of 40 ${ }^{\circ} \mathrm{C} / \mathrm{km}$ (Casshyap and Tewari, 1987). This suggests that at peak burial in the deeper parts of the basin the Permian formations probably exceeded $120^{\circ} \mathrm{C}$, at least in the deeper parts of the basin, and that a significant portion of the organic-rich shales reached peak thermal maturity during the Jurassic period, at least 150 my before present, as illustrated schematically in Fig. 3.

It is considered highly significant that those samples shown to be at peak-thermal maturity today, reached that thermal state so many millions of years ago. Reaching peak-thermal maturity such a long time ago is likely to have some impacts on the pyrolysis peak characteristics, pore-size distribution and geomechanical properties of these shales. Clearly, the less thermally mature shales sampled today must have been buried less deeply and uplifted to less-mature conditions more quickly than indicated schematically in Fig. 3. In addition, the sub-basins of the Domador Valley were impacted by igneous activity during the Cretaceous, associated with the Rajmahal flood basalt magmatism of the Eastern Indian Shield, which resulted in an intensive swarm of dolerite dykes penetrating the Permian Formations (Srivastava et al., 2009). These resulted in significant contact metamorphism of the adjacent organicrich shales, typically elevating their thermal maturity to postmature levels. Some samples in the dataset analysed by RockEval pyrolysis for this study have been affected by such contact metamorphism, which has provided them with very distinctive pyrolysis S2 peak characteristics.

\section{Analytical methodology}

The Rock-Eval pyrolysis and TOC analysis of the shale samples were carried out using a Rock-Eval 6 machine (Vinci Technologies). The sample weights used were up to $60 \mathrm{mg}$ for the BH series of samples following the appropriate guidelines for rocks type III-IV organic-matter (Hazra et al., 2017). The samples were crushed to less than 212 microns particle sizes and loaded into heating crucibles.

For the single-heating ramp $\left(25^{\circ} \mathrm{C} / \mathrm{min}\right)$ pyrolysis analysis (that used for samples BH-1 to BH-20, CG 1283, CG 1284, CG 1285, and CG 1286 and CG 812), the Rock-Eval 'basic method' was used. In this cycle, pyrolysis begins at 300 ${ }^{\circ} \mathrm{C}$ (initial temperature is kept at $300{ }^{\circ} \mathrm{C}$ for few minutes to establish isothermal temperature conditions). It is during this stage that the free thermo-vaporized hydrocarbons present within the samples are released and recorded as the S1 curve of the Rock-Eval pyrogram (Lafargue et al., 1998; Behar et al., 2001). The temperature is then increased in a ramped pattern, at a rate of $25{ }^{\circ} \mathrm{C} / \mathrm{min}$ up to a final temperature of $650{ }^{\circ} \mathrm{C}$. During this second stage $\left(300\right.$ to $\left.650{ }^{\circ} \mathrm{C}\right)$, the more tightly bound petroleum (i.e., within sealed pores and within the kerogen) is cracked and released and petroleum not yet generated from the kerogen is generated. These vapor contributions are eluted and register as the S2 curve of the Rock-Eval pyrogram (Lafargue et al., 1998; Behar et al., 2001). The S2 values thus represent the remaining petroleumgeneration potential of the samples.

The temperature where upon the highest magnitude of pyrolyzate is released during S2 stage of Rock-Eval, is known as the Rock-Eval S2-peak temperature and this is the metric on which this study is focused. The Tmax metric, although widely used as a proxy value for characterizing the degree of thermal maturity of a sample, is in fact an arbitrary machine correction applied to the S2 peak temperature. The correction typically applied is $\mathrm{Tmax}=$ Tpeak $\mathrm{S} 2-41{ }^{\circ} \mathrm{C}$ (when the Rock-Eval 


\section{HI versus S2 Peak Temperature Permian Shales Raniganj Basin (India)}

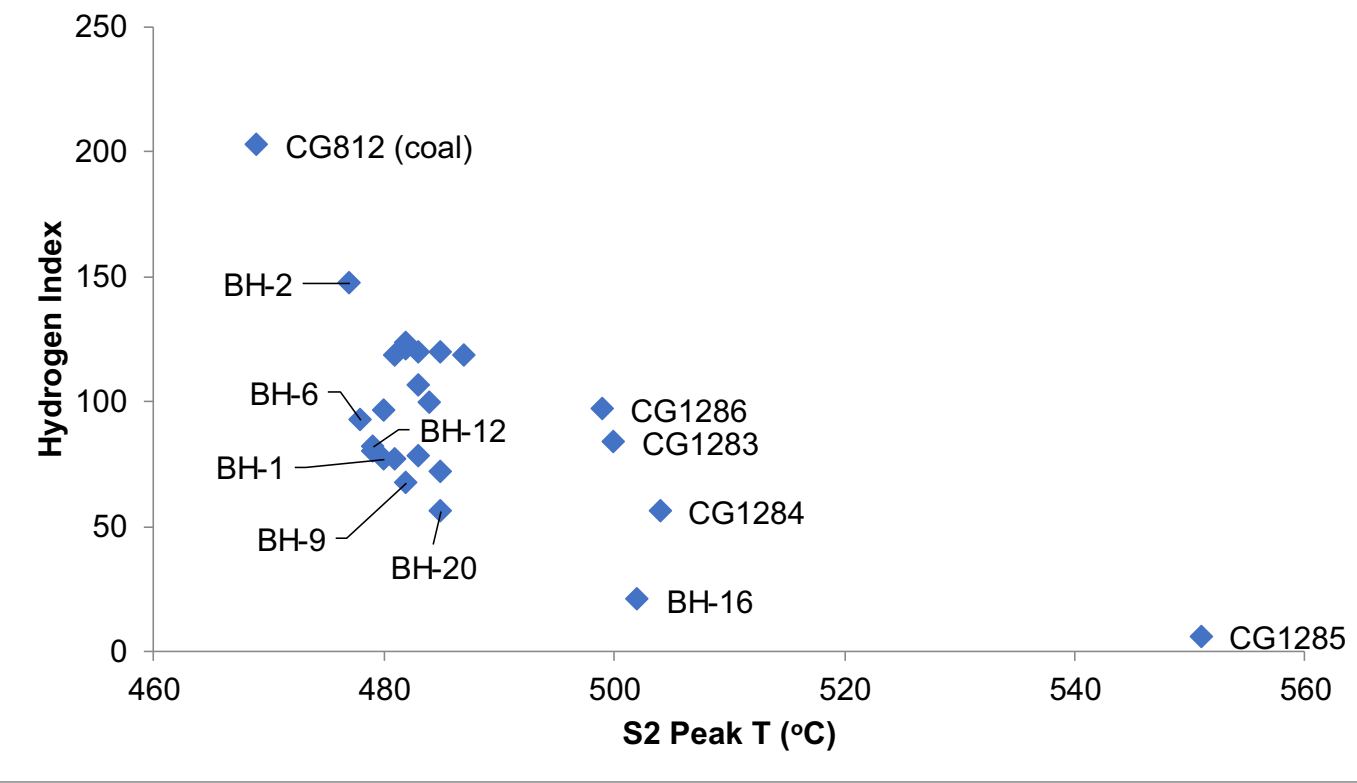

Fig. 4. The less mature samples plot towards the top left of this HI versus S2 peak temperature plot. The samples labelled are those used for more detailed S2-peak characterization analysis.

machine uses the 160,000 standard). As the S2-temperature in modern Rock-Eval equipment is recorded accurately the Tmax value is not that relevant for kinetic analysis, but of course has a positive correlation of near 1 with the S2 peak temperature.

The carbon dioxide $\left(\mathrm{CO}_{2}\right)$ and carbon monoxide $(\mathrm{CO})$ generated during the Rock-Eval pyrolysis stage are registered under the S3 curve of Rock-Eval. These are measured by an infrared detector within the equipment. The total pyrolyzable carbon (PC) content of the sample is computed from the hydrocarbons and carbon vapors released under S1, S2, and S3 curves. The pyrolysis stage is followed by the oxidation stage, during which the samples are automatically transferred to the oxidation oven, where the samples are heated to a final temperature of $850{ }^{\circ} \mathrm{C}$. During this stage, the remaining organic matter within the samples is burnt off, and thereby produces the residual carbon (RC) fraction. The sum of PC and $\mathrm{RC}$ provides the total organic carbon (TOC) measure for the sample (Lafargue et al., 1998; Behar et al., 2001).

To further characterize samples CG 1283, CG 1284, CG 1285, and CG 1286 and to obtain more constrained kerogen kinetics, these were subjected to two additional heating ramp experiments. The samples were prepared in the same way as for the single-heating-ramp measurements, i.e., crushed to < 212 microns particle size, loaded into crucibles. They were then analyzed using the two modified pyrolysis programs. In one cycle, the heating rate during pyrolysis was maintained at $5{ }^{\circ} \mathrm{C} / \mathrm{min}$, while in the other the heating rate was maintained at $15^{\circ} \mathrm{C} / \mathrm{min}$. The results from these two cycles for the abovementioned four samples were then compiled and compared with the results from the $25{ }^{\circ} \mathrm{C} / \mathrm{min}$ heating rate program. As our main objective was to study kerogen kinetics, no changes were made in the oxidation part of the analysis. The same Rock-Eval 6 equipment (Vinci Technologies) was used for conducting the analysis at all three heating ramps. The flame ionization detection (FID) counts are compiled in per degree $\mathrm{C}$ intervals between 300 and $650{ }^{\circ} \mathrm{C}$ to delineate the $\mathrm{S} 2$ peak in detail. It is these data, and the cumulative transformation factor derived from the FID increment data, that form the basis of the S2-peak shape and kinetic analysis conducted in this study.

\section{Analytical results}

The 25 selected samples from the Permian formations of the Raniganj basin were analysed by Rock-Eval. The samples consist of 24 shales and one coal. A listing of the summary Rock-Eval results, i.e., those typically used to characterize organic-rich samples are listed in Table 2.

All the samples (except BH-1-a silty shale) are marked by high-TOC content. These samples range from early maturity $\left(\mathrm{R}_{\mathrm{O}} \sim 0.6\right.$ for $\left.\mathrm{BH}-2\right)$ to post mature $\left(\mathrm{R}_{\mathrm{O}}>2.2 \%\right.$ for $\mathrm{CG}$ 1285 , one of two samples affected by contact metamorphism associated with Cretaceous-age igneous intrusion). Most of the samples are in the range early-peak thermal maturity to latepeak thermal maturity. Although rich in carbon (most are in the total organic carbon-TOC-range $5 \%$ to $11 \%$ ) the shales have hydrogen indices (HI) less than 150 (the majority less than 100) indicative of kerogen type III-type IV, gas-prone formations (Fig. 4). BH-16 has the highest Tmax value of samples from the Kabitirtha area as it is a heat-affected (i.e., contact metamorphism) shale, and with $\mathrm{R}_{\mathrm{o}}$ of $1.65 \%$ post-peak stage of thermal maturity. The other Kabitirtha samples are at the early to peak-stages of thermal maturity. 
Table 2. Rock-Eval summary data for 25 Permian samples from the Raniganj basin, India.

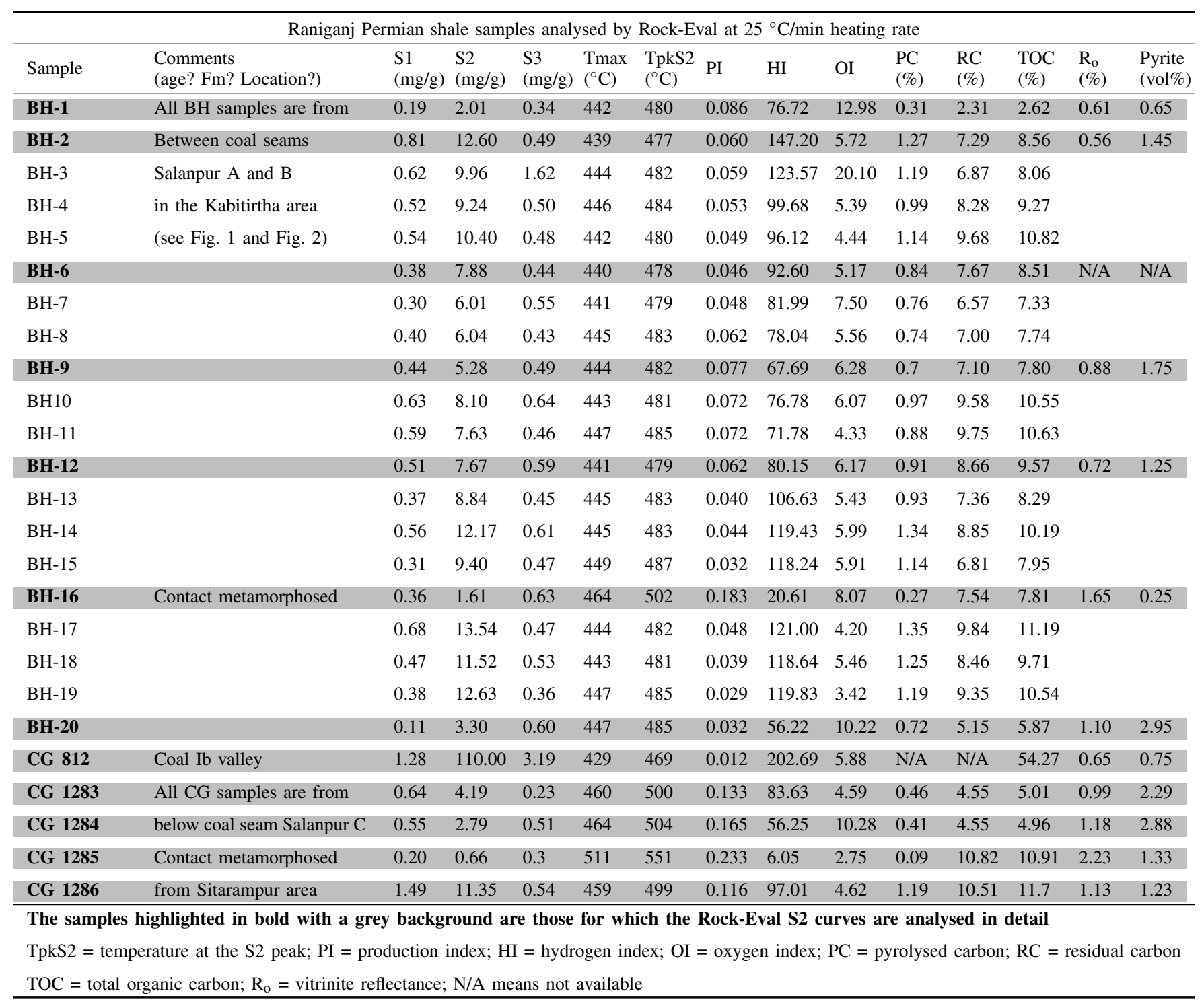

The shale samples all have a productivity index (PI) of less than 0.1 (Table 2), which is somewhat at odds with their level of thermal maturity. Formations at peak generation typically have PI values $\gg 0.1$ (Peters and Cassa, 1994). One explanation for this is that a significant amount of the gas generated has already escaped and migrated from the mature formations. Another explanation is that much of the gas already generated in these formations is trapped within the kerogen (both in the matrix kerogen and its nanopores), and the nanopores only release most of that gas during the S2-heating-ramp stage of pyrolysis (i.e., at temperatures of $>$ $300{ }^{\circ} \mathrm{C}$ ) as more gas enters those nanopores and causes them to grow/burst/coalesce. Both explanations, and other physical characteristics of the samples, may have contributed to the pyrograms generated from the samples of these formations studied by Rock-Eval analysis.

The Raniganj Permian shales have a very distinctive ge- ological/burial history. Many of the samples studied here reached peak thermal maturity many millions of years ago and have remained in that state up to the present day. Maximum thermal maturity was probably reached for most of these samples at some stage between 150 and 200 million years ago (Fig. 3). This means that some gas, and the kerogen it was produced, from have remained in that condition (i.e., mature kerogen with gas trapped in at least some of its nanopores) for a long period. All kinds of chemical interactions with percolating fluids and other formation components (e.g., pyrite and inertinite/charcoal) may have occurred between the time peak maturity was achieved and the present day. As shall be shown, the characters of the $\mathrm{S} 2$ peaks of the thermally-mature Raniganj basin samples are somewhat unusual. Although these can be explained primarily in terms of first order kinetic reactions, it seems more plausible that other physio-chemical processes are also contributing to these S2-peak characteris- 
Table 3. Summary of kerogen mineralogy for selected Raniganj basin samples. Organic matter is measured on a mineral matter free basis.

\begin{tabular}{|c|c|c|c|c|c|}
\hline \multicolumn{6}{|c|}{ Kerogen types in Permian shale \& coal samples analyzed by Rock-Eval } \\
\hline Sample number & $\begin{array}{l}\text { Vitrinite \% type III } \\
\text { humic / coaly }\end{array}$ & $\begin{array}{l}\text { Liptinite \% type II } \\
\text { planktonic }\end{array}$ & $\begin{array}{l}\text { Inertinite } \% \text { type IV non- } \\
\text { generating residue }\end{array}$ & $\begin{array}{l}\text { Total organic } \\
\text { matter Wt } \%\end{array}$ & Pyrite (vol\%) \\
\hline CG-1283 & $57.7 \%$ & $5.9 \%$ & $36.4 \%$ & 14.63 & 2.29 \\
\hline CG-1284 & $49.4 \%$ & $9.3 \%$ & $41.4 \%$ & 13.81 & 2.88 \\
\hline CG-1285 & $68.2 \%$ & $2.2 \%$ & $29.6 \%$ & 30.05 & 1.33 \\
\hline CG-1286 & $59.7 \%$ & $6.5 \%$ & $33.8 \%$ & 27.05 & 1.23 \\
\hline CG- 812 & $60.3 \%$ & $15.0 \%$ & $24.7 \%$ & 77.67 & 0.75 \\
\hline
\end{tabular}

tics.

We have conducted detailed analysis of the organic mineralogy and kerogen types present in some of the samples. This analysis is presented in summary in Table 3 .

What is revealing about the kerogen analysis (Table 3) is that the samples contain a mixture of kerogens (types III, IV and II, in that order of abundance). Type III kerogen is the dominant kerogen in these samples, but type IV and type II are present in significant amounts. Although the organic material (and TOC) present in the Raniganj shale samples is high, about one-third or more of it is inertinite (type IV non-petroleum generating oxidized organic matter), mainly composed of fossilized charcoal (e.g., fusinite and semi-fusinite). Except for the post-mature samples, about $50 \%$ to $60 \%$ of the kerogen is gas-prone type III (vitrinite) and about $5 \%$ to $10 \%$ is type II (liptinite). In the post-mature sample, the type III kerogen is almost $70 \%$ of the kerogen present and the quantity of type II kerogen is much reduced $(\sim 2 \%)$. The mixed-maceral nature of these samples is relevant to the detailed S2 peak interpretations of these samples.

\section{Pyrolysis S2 peak characterization}

\subsection{Kerogen kinetics modelling and S2 peak charac- terization}

Petroleum generation from the kerogen present in shales is traditionally modelled (since the 1970s/1980s) using Arrhenius (1889) first-order reaction kinetics (Tissot and Espitalie, 1975; Lerche et al., 1984; Tissot and Welte, 1984; Lewan, 1985; Wood, 1988). There are various approaches, but the one using the $\Sigma T T I_{A R R}$ time-temperature integral (Wood, 1988, 2017a) is a convenient one to calculate at geological and laboratory time scales. It models thermal maturity in terms of vitrinite reflectance and the petroleum transformation factors for kerogens other than vitrinite with reaction rates governed by different first-order reaction kinetics. The method is straight-forward to calculate because it uses single E-A pairs (where $\mathrm{E}$ is the activation energy of a reaction and $\mathrm{A}$ is the pre-exponential (frequency) factor, expressed on geologicaltime scales $\left(\mathrm{my}^{-1}\right)$ or laboratory time scales for pyrolysis experiments $\left(\mathrm{my}^{-1}\right.$ or $\mathrm{sec}^{-1}$ ), which may be varied to match the kinetics of specific kerogens or mixtures of kerogens. The mathematic formulations required to apply this method and its applications to various burial histories, kerogen mixing, and thermal maturity optimization analysis are described in some detail (Wood, 1988, 2017a, 2018a, 2018b).

The Arrhenius method of kinetic modelling of kerogen determines petroleum generation peaks and associated cumulative transformation factor (TF) profiles. The TF profiles represent the fraction of potential oil and/or gas yielded (on a 0 to 1 scale) from kerogens as they mature and pass through the oil and gas thermal generation windows, in accordance with their specific reaction kinetics. These peaks and TF profiles have relevance to the $\mathrm{S} 2$ peak generated by a Rock-Eval pyrogram. The conventional approach is to match single-heating-rate or (preferably) multi-heating-rate S2 pyrolysis peaks with such first-order kinetic equations (Lewan and Ruble, 2002).

There is some controversy as to how essential multi-rate pyrolysis is in defining meaningful E-A kinetic information that can be used to reliably model petroleum generation on the geological scale (Peters et al., 2015; Waples, 2016). Significant and useful information is provided by both approaches. However, the common approach of inverting kerogen kinetics from the S2 peaks of multi-heating-rate pyrograms using single A (Arrhenius equation pre-exponential term) values is hard to reconcile with realistic reaction processes on a geological or laboratory time scales for shales containing mixed kerogens (Wood, 2018a). Recent developments have shown that it is possible to invert kerogen kinetics from relatively limited (single-heating-rate) S2 peak characteristics in some cases (Chen et al., 2017) and that mixing of kerogens with different first-order reaction kinetics leave characteristic shape and form signatures in their petroleum transformation (TF) profiles (Wood, 2018a). As many shales, including those of the Raniganj basin analysed here, are made up of mixed macerals, there is scope to understand the impact of mixed macerals with different reaction kinetics (i.e., different E-A pairs) on the shape of their petroleum transformation profiles and to see whether these are reflected in the forms of their S2 peaks across a range of thermal maturities.

\subsection{Single-heating-rate $\left(25^{\circ} \mathrm{C} / \mathrm{min}\right)$ pyrograms}

There are several S2-peak-shape metrics that have been shown to be highly sensitive to the different reaction kinetics 
of mixed-maceral shales (Wood, 2018). For this reason, the detailed pyrogram data of selected Raniganj basin shale (and one coal) samples have been analysed to determine these characteristic S2 peak metrics. For the single-heating rate samples these metrics are listed in Table 4 and the actual S2 peaks and transformation profiles for these samples are illustrated in Figs. 5 and 6.

What is visually apparent from Figs. 5 and 6 is that the overall width of the S2 peak (left-side graphs) gradually increases from the lowest maturity to highest maturity shale samples. Also, a more significant right-side shoulder materializes as the samples become more thermally mature, and a smaller left-side shoulder to the S2 peak emerges in the most mature shales (this is a large and significant feature of the metamorphosed sample BH-16). The transformation profiles (right-side graphs) become progressively less-steep in the most-thermally-mature samples. Note the coal has the steepest transformation profile (i.e., the narrowest S2 peak). The coal ( $\mathrm{CG} \mathrm{812)}$ and the least mature shale (BH-2) display the most symmetrical S2 peaks. Clearly thermal maturity is influencing the S2 peaks for this suite of samples. It is for this reason that it is generally considered best practice to use immature samples to generate pyrograms for kerogen kinetics modelling and inversion. It is certainly easier to do so, but, as we shall reveal some kinetic insights can be gained from modelling thermally mature samples.

The metrics listed in Table 4 quantify some of the qualitative-S2-peak-shape characteristics described in the previous paragraph, particularly the transformation gradients and temperature intervals between certain transformation fractions (e.g., the temperature difference between $\mathrm{TF}=0.1$ and $\mathrm{TF}=$ $0.9)$. These metrics reveal characteristic signatures for the $S 2$ peaks and TF profiles of shale and coal formations that can be meaningfully modelled applying the $\sum T T I_{A R R}$ method.

\subsection{Multi-heating-rate $\left(25^{\circ} \mathrm{C} / \mathrm{min} ; 15^{\circ} \mathrm{C} / \mathrm{min} ; 5\right.$ ${ }^{\circ} \mathrm{C} / \mathrm{min}$ ) pyrograms}

The advantage of multi-rate pyrolysis analysis is that they provide more definitive constraints on the first-order kinetic reaction metrics (E-A values) (Sundararaman et al., 1992) that can be used in certain cases to successfully fit the multiple S2 peak characteristics generated. Usually, pyrograms at a minimum of three significantly different heating rates are recorded in multi-heating-rate analysis. This method often works well when there is a relative narrow range of kerogen types and kinetics involved (i.e., a single-dominant-kerogen species present in the formation). However, in cases where there are mixed macerals involved, with very different reaction kinetics, it means that the kinetic interpretations of S2 peaks are often not as straightforward as some pyrologists would like them to be. This was first pointed out by Sundararaman et al. (1992) by mixing liptinite and vitrinite with significantly different pre-exponential/frequency factors (A) they demonstrated that using a single value of A resulted in an incorrect distribution of activation energies. In such cases, there are typically multiple kinetic solutions that need to be considered before the reaction kinetics that govern petroleum transformation can be confirmed with confidence. Moreover, Stainforth (2009) pointed out that it is that rate at which petroleum can migrate through (i.e., escape from) the kerogen rather than the first-order generation reactions alone that determine the rate at which petroleum will free to migrate through the host shale and/or expelled from that source rock. As well as single or complex-parallel first-order kinetic reactions, secondary reactions and processes (e.g., geomechanical factors, catalysis, oil and natural gas liquid cracking) are likely to make significant contributions to the $\mathrm{S} 2$ peaks of many rocks, particularly those in a thermally mature state.

Characteristic S2 peak metrics recorded for the multiheating-rate pyrolysis of four selected Raniganj basin samples the classic Rock-Eval metrics are listed in Table 5 and details of the S2 peak characteristic metrics are provided in Table 6.

The higher S2 peak temperature (and Tmax), lower HI and higher PI stand out for the post-mature metamorphosed sample (CG 1285), compared to the other three samples (Table 5), which are at, or close to, peak-oil thermal maturity according to the vitrinite reflectance data. For those three samples there exists about a 25 to $30{ }^{\circ} \mathrm{C}$ temperature difference between the $\mathrm{S} 2$ peak at $5{ }^{\circ} \mathrm{C} / \mathrm{min}$ heating rate (lower temperature) and the $25{ }^{\circ} \mathrm{C} / \mathrm{min}$ heating rate. In addition to the S2 peak temperature the other shape characteristics of the S2 peak also differ in systematic ways between the faster and slower heating rate pyrograms. These differences match in terms of their trends the differences highlighted by Wood (2018) for models using the $\sum T T I_{A R R}$ kinetic model to generate transformation profiles for various kinetic (E-A) assumptions. Note the four samples described in Table 5 contain significant but variable quantities of pyrite. The presence of sulfur in the kerogen of organicrich shales is known to be an influencing factor potentially accelerating kerogen kinetics in some cases (Lewan, 1985). Sulfur in pyrite in the Raniganj samples does not directly indicate that there is sulfur present in the kerogen contained in those samples. However, the presence of high sulfur contents in those samples (indicated by their pyrite content) and the long-period of time that has elapsed since they reached thermal maturity suggests that sulfur may have played a catalytic role to accelerate their kerogen kinetics.

The S2 peak characterization metrics (Table 6), displayed over smaller temperature intervals than the data displayed in Table 3, reveal some distinctive features. Samples CG 1283, CG 1284 and CG 1286 are similar shales at similar levels of thermal maturity, all from the from Sitarampur area of Raniganj basin (as is CG 1285). It is, therefore reassuring that for those three samples the trends, changes and shapes of the S2 peaks vary in the same systematic way from the low heating rate to high heating rate pyrogram. Such S2-peak-shape consistency in these three samples confirms that the observed S2-shape characteristics are real and can potentially be modelled/replicated by kinetic analysis. There are subtle differences also in the S2 characteristics of these three samples. For instance, the S2 peak of sample CG 1286 is narrower than that for samples CG 1283 and CG 1284, as shown by the temperature differences between different $\mathrm{TF}$ values (Table 6). 


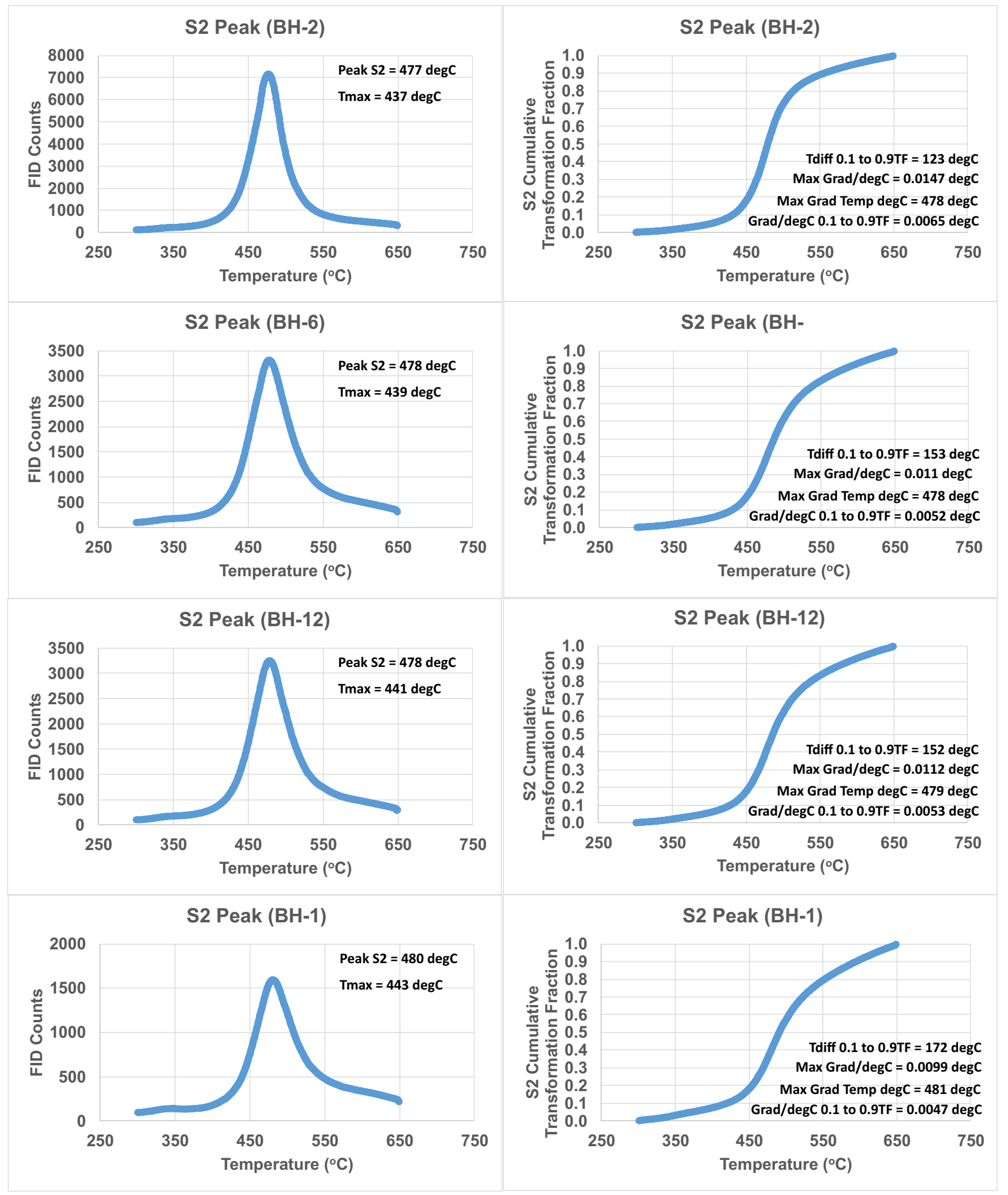

Fig. 5. Pyrogram (Rock-Eval) S2 peak (left) and cumulative transformation profile (right) arranged side by side for four shale samples of marginal to peak thermal maturity (least mature at the top see Table 1 and Table 3 for sample details). 

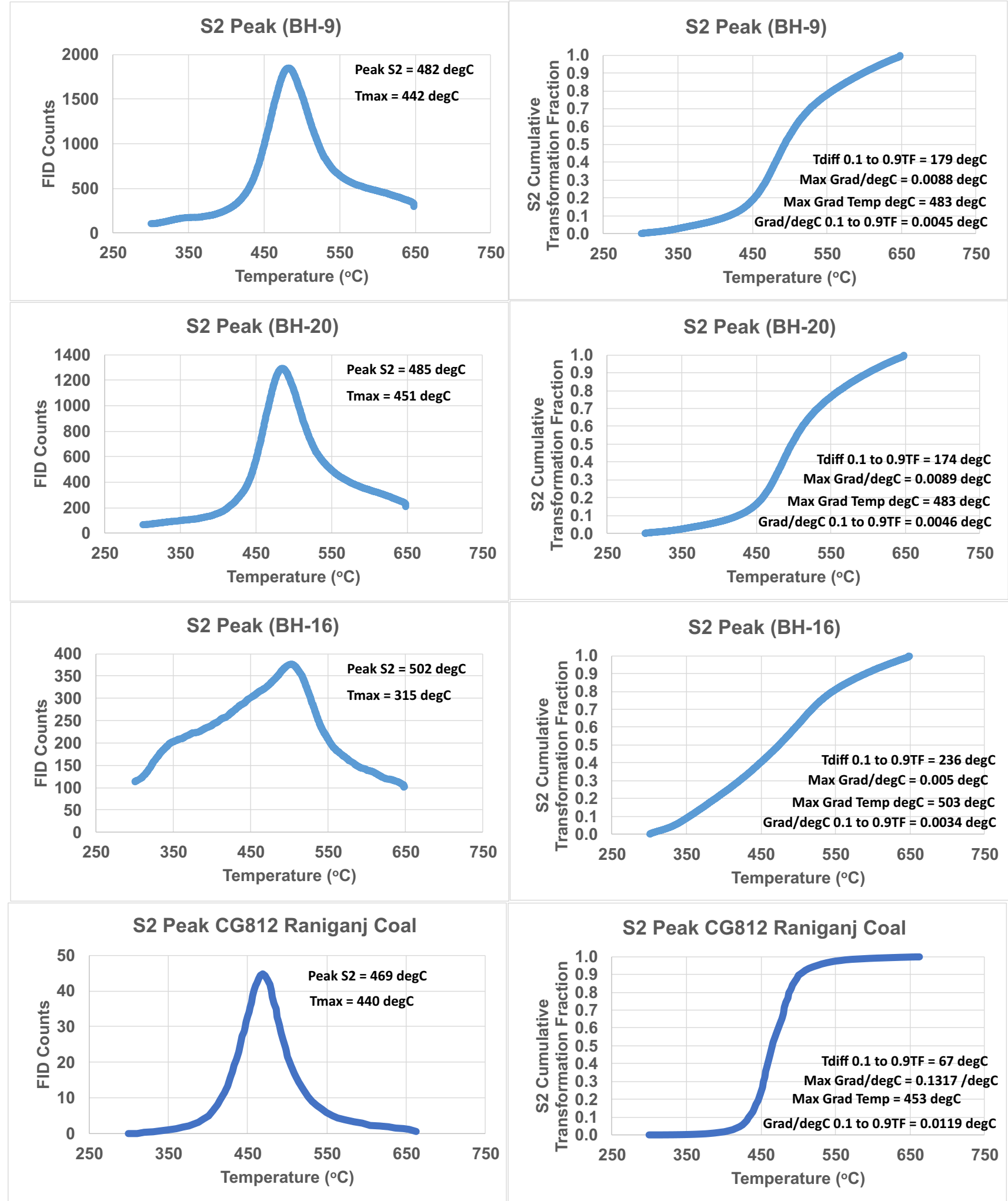

Fig. 6. Pyrogram (Rock-Eval) S2 peak (left) and cumulative transformation profile (right) arranged side by side for four samples: three shales of peak to post-peak thermal maturity and one early-mature coal-CG 812 (see Table 1 and Table 3 for sample details). Sample BH-16 has been thermally metamorphosed by an igneous intrusion. 
Table 4. Pyrolysis (Rock-Eval) S2 peak shape characteristics determined at a heating rate of $25^{\circ} \mathrm{C} / \mathrm{min}$ for selected Raniganj basin samples.

\begin{tabular}{|c|c|c|c|c|c|c|c|c|}
\hline All recorded at $25^{\circ} \mathrm{C} / \mathrm{min}$ heating rate & $\mathrm{BH}-1$ & $\mathrm{BH}-2$ & BH-6 & $\mathrm{BH}-12$ & BH-9 & $\mathrm{BH}-16$ & $\mathrm{BH}-20$ & $\begin{array}{l}\text { CG } 812 \\
\text { (Coal) }\end{array}$ \\
\hline TF gradient $/\left({ }^{\circ} \mathrm{C}\right)$ at $\mathrm{S} 2$ peak & 0.00986 & 0.01472 & 0.01097 & 0.01125 & 0.00880 & 0.00495 & 0.00891 & 0.01156 \\
\hline Tmax (corrected) or maximum FID increase & 443 & 437 & 439 & 441 & 442 & 464 & 451 & 440 \\
\hline $\mathrm{T}$ at $\mathrm{S} 2$ peak $\left({ }^{\circ} \mathrm{C}\right)$ & 481 & 478 & 478 & 479 & 483 & 503 & 483 & 469 \\
\hline Tpeak-Tmax $\left({ }^{\circ} \mathrm{C}\right)$ & 38 & 41 & 39 & 38 & 41 & 39 & 32 & 29 \\
\hline TF start temp $\left({ }^{\circ} \mathrm{C}\right)$ & 303 & 303 & 303 & 304 & 304 & 301 & 304 & 299 \\
\hline TF $1 \%$ temp $\left({ }^{\circ} \mathrm{C}\right)$ & 319 & 338 & 332 & 331 & 323 & 306 & 324 & 386 \\
\hline TF $10 \%$ temp $\left({ }^{\circ} \mathrm{C}\right)$ & 421 & 432 & 430 & 429 & 419 & 354 & 426 & 434 \\
\hline TF $90 \%$ temp $\left({ }^{\circ} \mathrm{C}\right)$ & 593 & 555 & 583 & 581 & 598 & 590 & 600 & 501 \\
\hline TF $99 \%$ temp $\left({ }^{\circ} \mathrm{C}\right)$ & 645 & 638 & 643 & 643 & 645 & 645 & 646 & 589 \\
\hline TF end temp $\left({ }^{\circ} \mathrm{C}\right)$ & 540 & 543 & 534 & 534 & 548 & 561 & 536 & 665 \\
\hline $\begin{array}{l}\text { Average } \mathrm{TF} \text { gradient } /\left({ }^{\circ} \mathrm{C}\right) \text { between } \mathrm{TF}= \\
0.1 \text { to } \mathrm{TF}=0.9\end{array}$ & 0.00465 & 0.00650 & 0.00523 & 0.00526 & 0.00447 & 0.00339 & 0.00460 & 0.01183 \\
\hline $\begin{array}{l}\text { Average } \mathrm{TF} \text { gradient } /\left({ }^{\circ} \mathrm{C}\right) \text { between } \mathrm{TF}= \\
0.01 \text { to } \mathrm{TF}=0.9\end{array}$ & 0.00301 & 0.00327 & 0.00315 & 0.00314 & 0.00304 & 0.00289 & 0.00304 & 0.00482 \\
\hline $\begin{array}{l}\text { Ratio of }(0.1 \text { to } 0.9) /(0.01 \text { to } 0.99) \mathrm{T} \text { differ- } \\
\text { ences }\end{array}$ & 0.5276 & 0.4100 & 0.4920 & 0.4872 & 0.5559 & 0.6962 & 0.5404 & 0.3318 \\
\hline Temperature difference 0.1 to $0.9\left({ }^{\circ} \mathrm{C}\right)$ & 172 & 123 & 153 & 152 & 179 & 236 & 174 & 67 \\
\hline Temperature difference 0.01 to $0.99\left({ }^{\circ} \mathrm{C}\right)$ & 326 & 300 & 311 & 312 & 322 & 339 & 322 & 203 \\
\hline Temperature difference start to end $\left({ }^{\circ} \mathrm{C}\right)$ & 237 & 240 & 231 & 230 & 244 & 260 & 232 & 366 \\
\hline 0.1 to 0.9 gradient / TF gradient at S2 peak & 0.47182 & 0.44191 & 0.47669 & 0.46802 & 0.50771 & 0.68448 & 0.51590 & 1.02344 \\
\hline TF fraction achieved at $\mathrm{S} 2$ peak & 0.4101 & 0.4847 & 0.4176 & 0.4284 & 0.4173 & 0.6311 & 0.3795 & 0.5542 \\
\hline
\end{tabular}

Table 5. Multi-heating rate Rock-Eval pyrolysis summary data for 4 selected Permian samples from the Ranganj basin, India. Vitrinite reflectance ( $\mathrm{R}_{\mathrm{o}} \%$ ) and pyrite contents are also included as they are relevant to the interpretation of these samples.

\begin{tabular}{|c|c|c|c|c|c|c|c|c|c|c|c|c|c|c|c|}
\hline \multicolumn{16}{|c|}{ Raniganj Permian shale samples analysed by Rock-Eval at three different heating rates } \\
\hline Sample & $\begin{array}{l}\text { Heating } \\
\left({ }^{\circ} \mathrm{C} / \mathrm{min}\right)\end{array}$ & rate & $\begin{array}{l}\mathrm{S} 1 \\
(\mathrm{mg} / \mathrm{g})\end{array}$ & $\begin{array}{l}\mathrm{S} 2 \\
(\mathrm{mg} / \mathrm{g})\end{array}$ & $\begin{array}{l}\text { S3 } \\
(\mathrm{mg} / \mathrm{g})\end{array}$ & $\begin{array}{l}\text { Tmax } \\
\left({ }^{\circ} \mathrm{C}\right)\end{array}$ & $\begin{array}{l}\text { TpkS2 } \\
\left({ }^{\circ} \mathrm{C}\right)\end{array}$ & PI & $\mathrm{HI}$ & OI & $\begin{array}{l}\mathrm{PC} \\
(\%)\end{array}$ & $\begin{array}{l}\mathrm{RC} \\
(\%)\end{array}$ & $\begin{array}{l}\text { TOC } \\
(\%)\end{array}$ & $\begin{array}{l}\mathrm{R}_{\mathrm{o}} \\
(\%)\end{array}$ & $\begin{array}{l}\text { Pyrite } \\
\text { (vol\%) }\end{array}$ \\
\hline \multirow{3}{*}{ CG 1283} & 5 & & 0.63 & 3.46 & 0.40 & 463 & 470 & 0.154 & 71.64 & 8.28 & 0.41 & 4.42 & 4.83 & 0.99 & 2.29 \\
\hline & 15 & & 0.65 & 3.88 & 0.23 & 461 & 490 & 0.143 & 78.23 & 4.64 & 0.45 & 4.51 & 4.96 & & \\
\hline & 25 & & 0.64 & 4.19 & 0.23 & 460 & 500 & 0.133 & 83.63 & 4.59 & 0.46 & 4.55 & 5.01 & & \\
\hline \multirow{3}{*}{ CG 1284} & 5 & & 0.57 & 2.60 & 2.06 & 470 & 477 & 0.180 & 53.72 & 42.56 & 0.44 & 4.40 & 4.84 & 1.18 & 2.88 \\
\hline & 15 & & 0.58 & 2.90 & 0.76 & 463 & 492 & 0.167 & 58.82 & 15.42 & 0.42 & 4.51 & 4.93 & & \\
\hline & 25 & & 0.55 & 2.79 & 0.51 & 464 & 504 & 0.165 & 56.25 & 10.28 & 0.41 & 4.55 & 4.96 & & \\
\hline \multirow{3}{*}{$\begin{array}{l}\text { CG } 1285 \\
\text { (metamorphosed) }\end{array}$} & 5 & & 0.20 & 0.47 & 0.25 & 503 & 510 & 0.299 & 4.56 & 2.43 & 0.07 & 10.23 & 10.30 & 2.23 & 1.33 \\
\hline & 15 & & 0.18 & 0.65 & 0.30 & 500 & 529 & 0.217 & 6.07 & 2.80 & 0.08 & 10.63 & 10.71 & & \\
\hline & 25 & & 0.20 & 0.66 & 0.30 & 511 & 551 & 0.233 & 6.05 & 2.75 & 0.09 & 10.82 & 10.91 & & \\
\hline \multirow{3}{*}{ CG 1286} & 5 & & 1.45 & 9.82 & 0.31 & 467 & 474 & 0.129 & 85.76 & 2.71 & 1.07 & 10.38 & 11.45 & 1.13 & 1.23 \\
\hline & 15 & & 1.46 & 10.58 & 0.52 & 463 & 492 & 0.121 & 90.97 & 4.47 & 1.13 & 10.50 & 11.63 & & \\
\hline & 25 & & 1.49 & 11.35 & 0.54 & 459 & 499 & 0.116 & 97.01 & 4.62 & 1.19 & 10.51 & 11.70 & & \\
\hline
\end{tabular}

$\mathrm{TpkS} 2$ = temperature at the S2 peak; PI = production index; $\mathrm{HI}=$ hydrogen index; OI = oxygen index; $\mathrm{PC}=$ pyrolysed carbon; $\mathrm{RC}=$ residual carbon TOC $=$ total organic carbon; $\mathrm{R}_{\mathrm{O}}=$ vitrinite reflectance; $\mathrm{N} / \mathrm{A}$ means not available 
Table 6. Pyrolysis (Rock-Eval) S2 peak shape characteristics determined at a three different heating rates for four selected thermally mature Raniganj basin samples. A thermally immature shale and coal sample at $25^{\circ} \mathrm{C} / \mathrm{min}$ heating rate are included for comparison.

\begin{tabular}{|c|c|c|c|c|c|c|c|c|c|c|c|c|c|c|}
\hline \multicolumn{15}{|c|}{ Raniganj basin Rock-Eval S2 peak shape metrics extracted from multi-rate pyrograms } \\
\hline \multirow[b]{2}{*}{$\begin{array}{l}\text { Rock-Eval S2-peak } \\
\text { descriptive metrics }\end{array}$} & \multicolumn{3}{|l|}{ CG 1283} & \multicolumn{3}{|l|}{ CG 1284} & \multicolumn{3}{|l|}{ CG 1285} & \multicolumn{3}{|l|}{ CG 1286} & \multirow{2}{*}{$\begin{array}{l}\mathrm{BH}-2 \\
25 \\
{ }^{\circ} \mathrm{C} / \mathrm{min}\end{array}$} & \multirow{2}{*}{$\begin{array}{l}\text { CG } 812 \\
25 \\
{ }^{\circ} \mathrm{C} / \mathrm{min} \\
\end{array}$} \\
\hline & $\begin{array}{l}5 \\
{ }^{\circ} \mathrm{C} / \mathrm{min} \\
\end{array}$ & $\begin{array}{l}15 \\
{ }^{\circ} \mathrm{C} / \min \\
\end{array}$ & $\begin{array}{l}25 \\
{ }^{\circ} \mathrm{C} / \mathrm{min} \\
\end{array}$ & $\begin{array}{l}5 \\
{ }^{\circ} \mathrm{C} / \min \\
\end{array}$ & $\begin{array}{l}15 \\
{ }^{\circ} \mathrm{C} / \min \\
\end{array}$ & $\begin{array}{l}25 \\
{ }^{\circ} \mathrm{C} / \min \\
\end{array}$ & $\begin{array}{l}5 \\
{ }^{\circ} \mathrm{C} / \mathrm{min} \\
\end{array}$ & $\begin{array}{l}15 \\
{ }^{\circ} \mathrm{C} / \mathrm{min} \\
\end{array}$ & $\begin{array}{l}25 \\
{ }^{\circ} \mathrm{C} / \min \\
\end{array}$ & $\begin{array}{l}5 \\
{ }^{\circ} \mathrm{C} / \mathrm{min} \\
\end{array}$ & $\begin{array}{l}15 \\
{ }^{\circ} \mathrm{C} / \mathrm{min} \\
\end{array}$ & $\begin{array}{l}25 \\
{ }^{\circ} \mathrm{C} / \mathrm{min}\end{array}$ & & \\
\hline $\begin{array}{l}\text { Transformation } \\
\text { gradient } /\left({ }^{\circ} \mathrm{C}\right) \text { at S2 peak }\end{array}$ & 0.006925 & 50.007416 & 50.009028 & 80.005362 & 20.003412 & 20.008241 & 10.004433 & 30.004226 & 0.005125 & 0.004758 & 0.010699 & 0.010508 & 0.017662 & 0.011559 \\
\hline $\mathrm{T}$ at $\mathrm{S} 2$ peak $\left({ }^{\circ} \mathrm{C}\right)$ & 470 & 490 & 500 & 477 & 494 & 504 & 511 & 538 & 551 & 473 & 491 & 499 & 477 & 469 \\
\hline $\mathrm{T}$ at TF Start $\left({ }^{\circ} \mathrm{C}\right)$ & 299 & 299 & 299 & 299 & 299 & 299 & 299 & 299 & 299 & 299 & 299 & 299 & 299 & 299 \\
\hline $\mathrm{T}$ at TF $0.01\left({ }^{\circ} \mathrm{C}\right)$ & 311 & 326 & 338 & 310 & 325 & 335 & 305 & 311 & 312 & 346 & 335 & 346 & 337 & 386 \\
\hline $\mathrm{T}$ at TF $0.05\left({ }^{\circ} \mathrm{C}\right)$ & 347 & 369 & 381 & 345 & 371 & 385 & 325 & 344 & 352 & 398 & 387 & 398 & 402 & 423 \\
\hline $\mathrm{T}$ at $\mathrm{TF} 0.10\left({ }^{\circ} \mathrm{C}\right)$ & 382 & 403 & 414 & 382 & 408 & 421 & 347 & 371 & 379 & 433 & 424 & 433 & 432 & 434 \\
\hline $\mathrm{T}$ at $\mathrm{TF} 0.20\left({ }^{\circ} \mathrm{C}\right)$ & 429 & 446 & 457 & 433 & 453 & 465 & 392 & 414 & 422 & 466 & 458 & 466 & 453 & 447 \\
\hline $\mathrm{T}$ at $\mathrm{TF} 0.30\left({ }^{\circ} \mathrm{C}\right)$ & 452 & 469 & 478 & 457 & 475 & 487 & 431 & 451 & 458 & 483 & 475 & 483 & 464 & 453 \\
\hline $\mathrm{T}$ at $\mathrm{TF} 0.40\left({ }^{\circ} \mathrm{C}\right)$ & 467 & 483 & 494 & 473 & 491 & 503 & 468 & 485 & 493 & 495 & 487 & 495 & 472 & 459 \\
\hline $\mathrm{T}$ at $\mathrm{TF} 0.50\left({ }^{\circ} \mathrm{C}\right)$ & 482 & 497 & 507 & 490 & 505 & 518 & 498 & 513 & 523 & 507 & 499 & 507 & 479 & 465 \\
\hline $\mathrm{T}$ at $\mathrm{TF} 0.60\left({ }^{\circ} \mathrm{C}\right)$ & 499 & 512 & 523 & 511 & 523 & 536 & 525 & 537 & 547 & 520 & 512 & 520 & 486 & 473 \\
\hline $\mathrm{T}$ at $\mathrm{TF} 0.70\left({ }^{\circ} \mathrm{C}\right)$ & 523 & 532 & 541 & 537 & 545 & 558 & 554 & 562 & 572 & 536 & 529 & 536 & 496 & 480 \\
\hline $\mathrm{T}$ at $\mathrm{TF} 0.80\left({ }^{\circ} \mathrm{C}\right)$ & 555 & 560 & 568 & 570 & 574 & 586 & 591 & 590 & 599 & 561 & 555 & 561 & 513 & 488 \\
\hline $\mathrm{T}$ at $\mathrm{TF} 0.90\left({ }^{\circ} \mathrm{C}\right)$ & 603 & 603 & 608 & 616 & 615 & 625 & 643 & 630 & 636 & 602 & 597 & 602 & 554 & 501 \\
\hline $\mathrm{T}$ at $\mathrm{TF} 0.95\left({ }^{\circ} \mathrm{C}\right)$ & 640 & 637 & 640 & 651 & 645 & 653 & 670 & 660 & 664 & 636 & 630 & 636 & 594 & 524 \\
\hline $\mathrm{T}$ at $\mathrm{TF} 0.99\left({ }^{\circ} \mathrm{C}\right)$ & 685 & 682 & 681 & 689 & 686 & 689 & 693 & 693 & 694 & 681 & 678 & 681 & 638 & 589 \\
\hline $\mathrm{T}$ at $\mathrm{Tf}$ end $\left({ }^{\circ} \mathrm{C}\right)$ & 699 & 698 & 696 & 699 & 699 & 698 & 699 & 700 & 698 & 696 & 697 & 696 & 649 & 665 \\
\hline $\mathrm{TF}$ reached at $\mathrm{S} 2$ peak & 0.41706 & 0.44627 & 0.44785 & 0.42286 & 0.42188 & 0.41058 & 0.54738 & 0.60330 & 0.61571 & 0.23775 & 0.43337 & 0.43253 & 0.47606 & 0.55420 \\
\hline $\mathrm{T}$ diff start to end $\left({ }^{\circ} \mathrm{C}\right)$ & 399.9 & 398.9 & 396.8 & 400.0 & 400.1 & 398.6 & 400.3 & 400.6 & 398.7 & 397.3 & 398.0 & 397.3 & 349.9 & 366.2 \\
\hline $\mathrm{T}$ diff 0.01 to $0.99 \mathrm{TF}\left({ }^{\circ} \mathrm{C}\right)$ & 374.4 & 356.0 & 343.2 & 378.8 & 360.7 & 353.7 & 388.6 & 381.5 & 381.5 & 334.4 & 342.6 & 334.4 & 301.1 & 203.3 \\
\hline $\mathrm{T}$ diff 0.05 to $0.95 \mathrm{TF}\left({ }^{\circ} \mathrm{C}\right)$ & 293.0 & 267.3 & 258.2 & 306.1 & 274.1 & 268.7 & 345.3 & 316.7 & 311.7 & 237.5 & 243.0 & 237.5 & 192.0 & 101.2 \\
\hline $\mathrm{T}$ diff 0.10 to $0.90 \mathrm{TF}\left({ }^{\circ} \mathrm{C}\right)$ & 221.0 & 200.2 & 193.9 & 234.6 & 207.0 & 204.1 & 295.7 & 259.5 & 256.3 & 168.8 & 172.1 & 168.8 & 122.5 & 67.6 \\
\hline $\mathrm{T}$ diff 0.20 to $0.80 \mathrm{TF}\left({ }^{\circ} \mathrm{C}\right)$ & 126.5 & 113.4 & 110.7 & 137.3 & 120.4 & 121.7 & 199.6 & 176.6 & 177.2 & 95.5 & 96.2 & 95.5 & 60.1 & 41.0 \\
\hline $\mathrm{T}$ diff 0.30 to $0.70 \mathrm{TF}\left({ }^{\circ} \mathrm{C}\right)$ & 71.3 & 63.2 & 62.7 & 80.0 & 69.5 & 71.2 & 122.7 & 110.7 & 113.4 & 53.7 & 53.9 & 53.7 & 32.2 & 27.3 \\
\hline $\mathrm{T}$ diff 0.40 to $0.60 \mathrm{TF}\left({ }^{\circ} \mathrm{C}\right)$ & 32.0 & 28.5 & 29.0 & 37.5 & 31.8 & 33.8 & 57.6 & 52.5 & 54.5 & 25.1 & 24.8 & 25.1 & 14.4 & 14.2 \\
\hline Avg $\mathrm{TF} /{ }^{\circ} \mathrm{C}$ start to end & 0.00250 & 0.00251 & 0.00252 & 0.00250 & 0.00250 & 0.00251 & 0.00250 & 0.00250 & 0.00251 & 0.00252 & 0.00251 & 0.00252 & 0.00286 & 0.00273 \\
\hline Avg $\mathrm{TF} /{ }^{\circ} \mathrm{C} 0.01$ to $0.99 \mathrm{TF}$ & 0.00262 & 0.00275 & 0.00286 & 0.00259 & 0.00272 & 0.00277 & 0.00252 & 0.00257 & 0.00257 & 0.00293 & 0.00286 & 0.00293 & 0.00325 & 0.00482 \\
\hline Avg $\mathrm{TF} /{ }^{\circ} \mathrm{C} 0.05$ to $0.95 \mathrm{TF}$ & 0.00307 & 0.00337 & 0.00349 & 0.00294 & 0.00328 & 0.00335 & 0.00261 & 0.00284 & 0.00289 & 0.00379 & 0.00370 & 0.00379 & 0.00469 & 0.00889 \\
\hline Avg $\mathrm{TF} /{ }^{\circ} \mathrm{C} 0.10$ to $0.90 \mathrm{TF}$ & 0.00362 & 0.00400 & 0.00413 & 0.00341 & 0.00387 & 0.00392 & 0.00270 & 0.00308 & 0.00312 & 0.00474 & 0.00465 & 0.00474 & 0.00653 & 0.01183 \\
\hline Avg $\mathrm{TF} /{ }^{\circ} \mathrm{C} 0.20$ to $0.80 \mathrm{TF}$ & 0.00474 & 0.00529 & 0.00542 & 0.00437 & 0.00498 & 0.00493 & 0.00301 & 0.00340 & 0.00339 & 0.00629 & 0.00624 & 0.00629 & 0.00999 & 0.01462 \\
\hline Avg $\mathrm{TF} /{ }^{\circ} \mathrm{C} 0.30$ to $0.70 \mathrm{TF}$ & 0.00561 & 0.00633 & 0.00638 & 0.00500 & 0.00575 & 0.00561 & 0.00326 & 0.00361 & 0.00353 & 0.00744 & 0.00742 & 0.00744 & 0.01244 & 0.01465 \\
\hline Avg $\mathrm{TF} /{ }^{\circ} \mathrm{C} 0.40$ to $0.60 \mathrm{TF}$ & 0.00625 & 0.00702 & 0.00690 & 0.00534 & 0.00630 & 0.00592 & 0.00347 & 0.00381 & 0.00367 & 0.00798 & 0.00805 & 0.00798 & 0.01386 & 0.01409 \\
\hline $\begin{array}{l}\text { Ratio }(0.1 \text { to } 0.9) /(0.01 \text { to } \\
0.99) \mathrm{T} \text { differences }\end{array}$ & 0.59030 & 0.56252 & 0.56496 & 0.61937 & 0.57373 & 0.57689 & 0.76097 & 0.68013 & 0.67190 & 0.50482 & 0.50221 & 0.50482 & 0.40697 & 0.33249 \\
\hline $\begin{array}{l}0.1 \text { to } 0.9 \text { gradient/TF gra- } \\
\text { dient at } \mathrm{S} 2 \text { peak }\end{array}$ & 0.52271 & 0.53876 & 0.45696 & 0.63604 & 1.13298 & 0.47574 & 0.61026 & 0.72955 & 0.60906 & 0.99603 & 0.43458 & 0.45097 & 0.36965 & 1.02375 \\
\hline
\end{tabular}

The trends, changes and shapes of the S2 peaks at different heating rates for the post-mature, metamorphosed sample CG 1285 are more extreme and quite distinct from the other three peak-mature samples. This confirms S2-peak broadening, among other changes, that are clearly linked to different levels of thermal maturity. However, these differences (i.e., changed S2-peak shape characteristics) may not all be caused by kinetic factors. Potentially several distinct physio-chemical processes may be involved in changing the S2-peak characteristics of the Permian shale formation in question. All the multi-rate pyrogram S2-shape characteristics are quite distinct from those of the immature shale (BH-2; Fig. 5) and coal (CG 812; Fig. 6 ), which are included in the final two columns of Table 6 for comparison.

Having described the characteristics and shapes of the S2 peaks for samples analyses by single-rate and multi-rate pyrolysis in quantitative terms, some key differences due to maturity and lithology (shale versus coal) are clearly observed. However, some key questions remain to be answered: 1) can these S2 shapes be meaningfully modelled and explained in 


\section{Metrics E versus Ln(A) for Kerogen Kinetic Optimization Modelling \& Fitting}

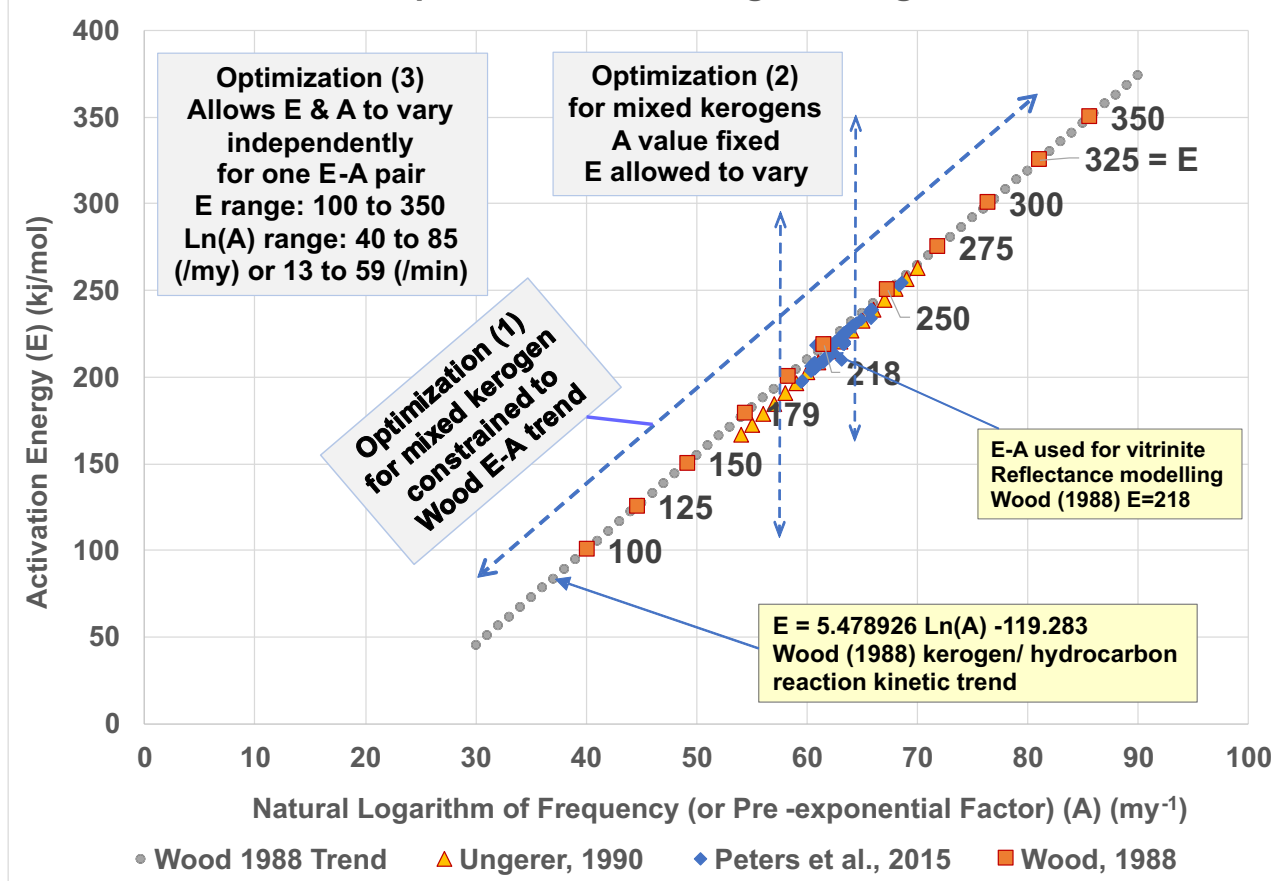

Fig. 7. Established trend of Arrhenius equation E-A kinetic metrics which many kerogens measured by pyrolysis are known to lie on or close to (Wood, 1988, 2017).

terms of first-order kerogen kinetics using the $\sum T T I_{A R R}$ kinetic model? 2) are other chemical processes (e.g., catalysis and higher order reactions) involved? 3) could the evolution of the pore-size distribution with thermal maturity represent one of perhaps several physical geomechanical rock properties that in some way influence certain form characteristics of the S2 peak? and, 4) can the quantified S2-peak shape metrics potentially be used as an exploration/exploitation tool to identify petroleum production "sweet spots"? The next section discusses alternative ways in which the S2 peak data can be modelled and interpreted, and how some insight can be gained regarding all four questions just posed.

\section{Modelling the S2-peak shape applying $\sum T T I_{A R R}$ kinetic model and optimizers}

The S2-peak-quantified characteristics, described in section 8 , are modelled applying the $\sum T T I_{A R R}$ kinetic kerogen transformation technique (Wood, 1988, 2017) applying optimizers in three distinct ways (Fig. 7): (1) locating multiple E-A kinetic metric pairs along a well-established kerogen-kinetic E-A trend, to which a significant body of published kerogen kinetic data conform, and applying that to match single-rate and multirate pyrogram data; (2) for multi-rate pyrogram data, selecting an A value that is able to approximately reproduce the S2 peak temperatures at different heating rates and then searching for $E$ values associated with that fixed-A value that can best match the pyrogram characteristics; and, (3) finding the single E-A pair that best matches the S2 peak temperatures of the three significantly different heating rates of the multi-rate pyrograms without constraining those E-A pairs to lie along the welldefined kerogen trend, but defining a discrete distribution of $\mathrm{E}$ values for a fixed value of A (i.e., in accordance with the principles originally suggested by Sundararaman et al., 1992). In optimization method (3) as applied here, the E-A values are allowed to vary within a wide range of potential values: E from 100 to $350 \mathrm{~kJ} / \mathrm{mol}$; and, LnA 40 to 85 (/my) (equivalent to LnA 13 to 59 ( $/ \mathrm{min}$ ) used for pyrolysis/laboratory scale modelling). For optimization approaches (1) and (2) a customized firefly optimization algorithm already applied to burial history modelling (Wood, 2018b) was used. For optimization approach (3) Excel's standard Solver optimizer was applied followed by adjusting E-value fractions along a constant A trend to match the S2-peak shapes more precisely (i.e., smoothing the fits). These minor smoothing adjustments are also verified by optimization method (2) or an "E-constant A" mixing algorithm for mixed-maceral solutions. The results of all three of these approaches are presented and compared.

\subsection{Optimizing S2-peak shape fitting constrained to the "known" kerogen E-A trend (Opt. 1)}

The fact that kerogens follow a well-established trend of E-A kinetic values was suggested in the 1970s (Tissot and Espitalie, 1975) and refined in the 1980s (Wood, 1988). It has been further defined and confirmed by various studies since then (Ungerer, 1990; Wood, 2017). That E-A trend is shown in summary form in Fig. 7 together with some selected kerogens. The dashed trend is determined by the expression 
$\mathrm{E}=5.478926$ LnA-119.283 (where Ln means the natural logarithm) proposed by Wood (1988). In this approach that trend is applied as a constraint to the optimizer when seeking fits to the S2 peaks of the samples. In situations where the samples are immature, and the kerogen is of one dominant type, this approach works well in locating the kerogen kinetics that best fit the $\mathrm{S} 2$ peak. For mixed macerals there are typically multiple possible solutions involving multiple E-A pairs. The optimizer is limited to select a maximum of ten E-A pairs from along the constraining trend (Fig. 7) in various fractions (0 to 1 ) with all fractions selected adding to 1 .

This optimization (1) approach works reasonably well in matching the S2 peak temperature and general S2-peak shape, without producing an exact peak fit, for the immature shale and coal Permian samples from the Raniganj basin (BH-2 and CG 812) as illustrated in Figs. 8 and 9 (upper graphs). The mixtures of kinetic E-A pairs identified to produce the best fits are listed in Table 7.

The optimizer can select and prioritize (by applying weighting factors) certain of the S2-peak characteristics listed in table 5 to target in identifying optimum fits to the measured S2-peak data. In this study those regions of the S2 peak excluding the left and right flanks (peak shoulders) are prioritized, as the data in that portion of the S2 peak is more statistically reliable (i.e., much higher counts recorded). Here, the following metrics (with their weighting factors, $1=$ low priority; $5=$ highest priority) contributed to a function test calculation that the optimizer strives to minimize:

Temperature at $\mathrm{S} 2$ peak $\left({ }^{\circ} \mathrm{C}\right)$ : weight applied $=5$;

Temperature at $\mathrm{TF} 0.50\left({ }^{\circ} \mathrm{C}\right)$ : weight applied $=5$;

Temperature difference between 0.20 to $0.80 \mathrm{TF}\left({ }^{\circ} \mathrm{C}\right)$ : weight applied $=3$;

Temperature difference between 0.30 to $0.70 \mathrm{TF}\left({ }^{\circ} \mathrm{C}\right)$ : weight applied $=3$;

Temperature difference between 0.40 to $0.60 \mathrm{TF}\left({ }^{\circ} \mathrm{C}\right)$ : weight applied $=3$;

Temperature difference between 0.05 to $0.95 \mathrm{TF}\left({ }^{\circ} \mathrm{C}\right)$ : weight applied $=1$;

Temperature difference between 0.10 to $0.90 \mathrm{TF}\left({ }^{\circ} \mathrm{C}\right)$ : weight applied $=1$;

Transformation factor (TF) reached at S2 peak: weight applied $=1$.

All the other S2 characteristics listed in Table 6 did not contribute to the function test calculation. Just the eightmetrics listed were used to identify the "best" fits. The optimizer compares the measured S2 peak TF profile with the calculated TF profile for a mixture of up to ten kerogen E-A values along the defined trend (Fig. 7) for each onedegree- $\mathrm{C}$ temperature interval and generates a function test score based on the metrics listed. The greater the weighted differences between the measured and calculated TF profiles the high the calculated function test will be. The optimizer strives to minimize that function test score by calculating TF profiles for a large population of mixed E-A pairs, ranking the results and modifying the E-As to progressively reduce the function test score over many iterations. While the actual optimization comparisons are conducted using the right-side curves (the TF profiles in Figs. 8 and 9) the results are also displayed in terms of reaction increments revealing the leftside S2 Peak shape matches (Figs. 8 and 9).

Sensitivity analysis of the optimization (1) process, using different S2-shape metrics from Table 5 and applying different weights in the function test calculation, showed that other combinations of metrics could not improve upon these matches, i.e., were unable to match precisely the right-side shoulders of the S2 peaks for these samples.

The best E-A fits achieved for the single-heating-rate S2 peak $\left(25^{\circ} \mathrm{C} / \mathrm{min}\right)$ immature-shale samples (BH-2 and $\mathrm{CG} 812$ ) involve the dominant contributions from $\sim \mathrm{E}=230 \mathrm{~kJ} / \mathrm{mol}$, but with significant contributions from lower and higher E-A values (Table 7). This mixture of E-A values is consistent with the mixed-maceral components observed in the Raniganj shale and coal samples.

For the peak-mature shale sample CG 1286, the best EA fits (Opt. 1 method) achieved for the multi-heating-rate $\mathrm{S} 2$-peaks involve the dominant contributions from $\sim \mathrm{E}$ values between 180 and $210 \mathrm{~kJ} / \mathrm{mol}$ and significant contributions from $\mathrm{E}=130$ (driven by the exaggerated right-side shoulder of the measured S2 peak in this sample) (Table 7 and Fig. 10). These "best fits" fail to match either shoulder of the S2 peak but do in the case of the $25^{\circ} \mathrm{C} / \mathrm{min}$ and the $15{ }^{\circ} \mathrm{C} / \mathrm{min}$ heating rates match the S2 peak temperatures and central parts of the S2 peak shapes reasonably well. However, the measured versus calculated "best" fit for the $5{ }^{\circ} \mathrm{C} / \mathrm{min}$ heating rate fails to match the $\mathrm{S} 2$ peak temperature.

For the post-mature shale sample CG 1285, the best E-A fits (Opt. 1 method) achieved for the multi-heating-rate S2peaks involve the dominant contributions from much lower $\mathrm{E}$ values between 110 and $140 \mathrm{~kJ} / \mathrm{mol}$. These fits are poor and fail to match the overall broad S2-peak shape and, in particular, the enhanced left-side shoulder (Table 7 and Fig. 11).

These results suggest that kerogen kinetics alone, mixing kinetics from the established kerogen E-A trend (Opt. 1, Fig. 7), cannot adequately explain all the characteristics of the S2 peaks of the Raniganj samples; particularly so for the more mature samples.

\subsection{Optimizing S2-peak shape fitting constrained to a specific $A$ value on the kerogen $E-A$ trend (Opt. 2)}

Similar optimization results are obtained using optimization method (2) (Opt. 2). In this case, A values are selected from the established E-A trend (Fig. 7) that best match the S2 peak temperatures of the pyrograms. The optimizer, using the same function test and weightings described for Opt. 1 then finds the best mix of E values that match the S2 shapes. Almost identical "best fits" are achieved by this method (Figs. 8 to 11), as shown by the adjacent locations of graphics showing the results for Opt. 1 and Opt. 2. As for Opt. 1 the fits for the slowest-heating-rate pyrograms are the worst and this method also struggles to fit the exaggerated shoulders of the S2 peaks of the more thermally mature samples.

These results suggest that kerogen kinetics alone, mixing kinetics along a single A trend (vertical line on Fig. 7) extending to either side of the established kerogen E-A trend 
Table 7. Kinetic modelling to achieve fits to S2 shapes by applying optimization methods (1) and (2) for three shales and one coal sample at various stages of thermal maturity from the Raniganj basin.

\begin{tabular}{|c|c|c|c|c|c|c|c|c|}
\hline \multicolumn{9}{|c|}{ Optimized S2 peaks kinetic solutions in terms of E-A contributions } \\
\hline \multirow{3}{*}{ Sample \# } & \multicolumn{4}{|c|}{ Optimization method (1) } & \multicolumn{4}{|c|}{ Optimization method (2) } \\
\hline & \multicolumn{4}{|c|}{ E-A Pairs constrained to Wood's Kerogen Line } & \multicolumn{4}{|c|}{ A fixed and E allowed to vary } \\
\hline & $\begin{array}{l}\text { Fraction } \\
\text { (smoothed) }\end{array}$ & $\begin{array}{l}\mathrm{E} \\
(\mathrm{kJ} / \mathrm{mol})\end{array}$ & $\begin{array}{l}\text { LnA } \\
(/ \mathrm{min})\end{array}$ & $\begin{array}{l}\text { LnA } \\
(/ m y)\end{array}$ & $\begin{array}{l}\text { Fraction } \\
\text { (smoothed) }\end{array}$ & $\begin{array}{l}\mathrm{E} \\
(\mathrm{kJ} / \mathrm{mol})\end{array}$ & $\begin{array}{l}\text { LnA } \\
(/ \min )\end{array}$ & $\begin{array}{l}\mathrm{LnA} \\
(/ \mathrm{my})\end{array}$ \\
\hline \multirow{5}{*}{$\begin{array}{l}\mathrm{BH}-2 \\
\mathrm{R}_{\mathrm{o}}=0.56 \\
\text { shale } \\
\text { good fit }\end{array}$} & 0.240 & 174 & 26.54 & 53.53 & 0.200 & 243 & 39.86 & 66.85 \\
\hline & 0.230 & 227 & 36.21 & 63.20 & 0.500 & 247 & 39.86 & 66.85 \\
\hline & 0.150 & 234 & 37.49 & 64.48 & 0.300 & 257 & 39.86 & 66.85 \\
\hline & 0.200 & 249 & 40.23 & 67.22 & & & & \\
\hline & 0.180 & 270 & 44.06 & 71.05 & & & & \\
\hline \multirow{4}{*}{$\begin{array}{l}\text { CG } 812 \\
R_{o}=0.65 \\
\text { coal } \\
\text { good fit }\end{array}$} & 0.150 & 214 & 33.84 & 60.83 & 0.250 & 275 & 45.34 & 72.33 \\
\hline & 0.500 & 230 & 36.76 & 63.75 & 0.500 & 277 & 45.34 & 72.33 \\
\hline & 0.200 & 280 & 45.89 & 72.88 & 0.250 & 285 & 45.34 & 72.33 \\
\hline & 0.150 & 320 & 53.19 & 80.18 & & & & \\
\hline \multirow{4}{*}{$\begin{array}{l}\text { CG } 1286 \\
R_{o}=1.13 \\
\text { shale } \\
\text { poor fit }\end{array}$} & 0.300 & 130 & 18.51 & 45.50 & 0.600 & 185 & 28.91 & 55.90 \\
\hline & 0.100 & 182 & 28.00 & 54.99 & 0.300 & 192 & 28.91 & 55.90 \\
\hline & 0.300 & 186 & 28.73 & 55.72 & 0.100 & 200 & 28.91 & 55.90 \\
\hline & 0.300 & 210 & 33.11 & 60.10 & & & & \\
\hline \multirow{3}{*}{$\begin{array}{l}\text { CG } 1285 \\
\mathrm{R}_{\mathrm{o}}=2.23 \\
\text { shale } \\
\text { v. poor fit }\end{array}$} & 0.300 & 110 & 14.86 & 41.85 & 0.200 & 126 & 19.24 & 46.23 \\
\hline & 0.400 & 125 & 17.60 & 44.59 & 0.500 & 136 & 19.24 & 46.23 \\
\hline & 0.300 & 137 & 19.79 & 46.78 & 0.300 & 150 & 19.24 & 46.23 \\
\hline
\end{tabular}

S2 Peak TF Match $25^{\circ} \mathrm{C} / \mathrm{min}$ ) for Sample BH-2

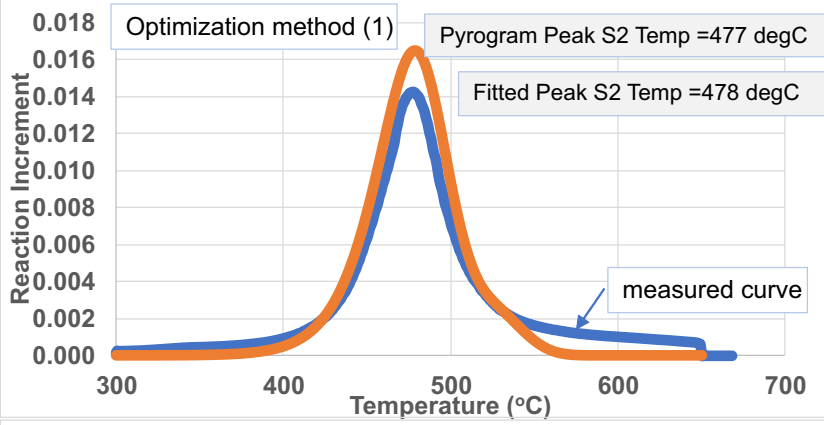

S2 Peak Match $\left(25^{\circ} \mathrm{C} / \mathrm{min}\right)$ for Sample BH-2

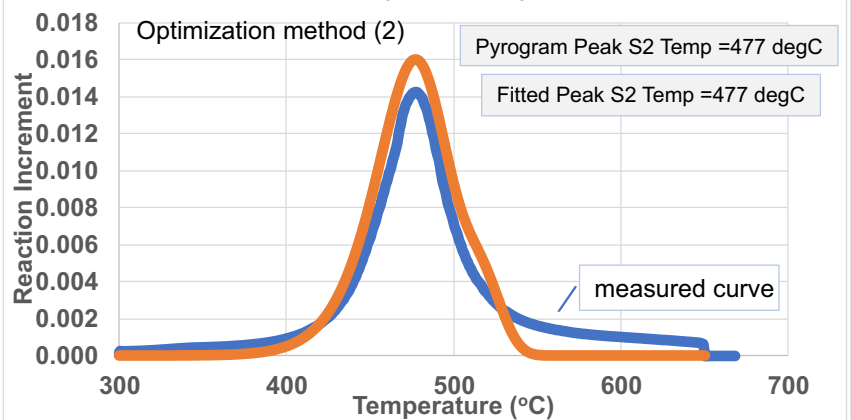

S2 Peak TF Match $25^{\circ} \mathrm{C} / \mathrm{min}$ ) for Sample BH -2
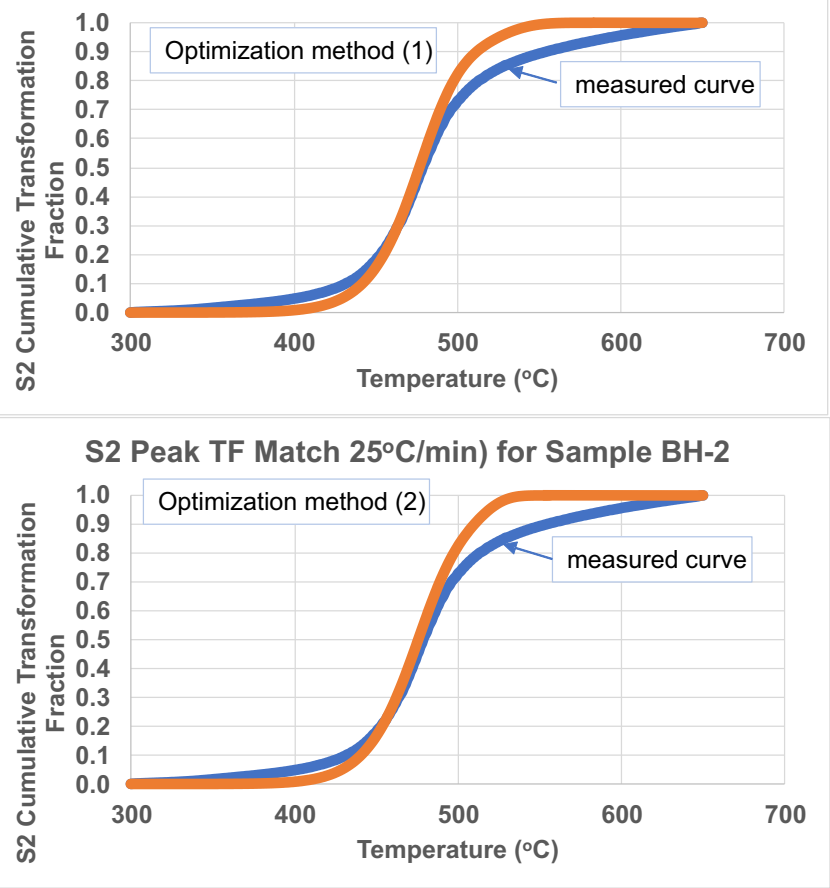

Fig. 8. Measured versus modelled $\mathrm{S} 2$ peak for early-mature Raniganj basin shale sample $\mathrm{BH}-2\left(\mathrm{R}_{\mathrm{o}}=0.56 \%\right)$ using to different optimization methods $(1)$ upper graphs (2) lower graphs. See text for explanation of kinetic solutions used to derive the modelled curves. 

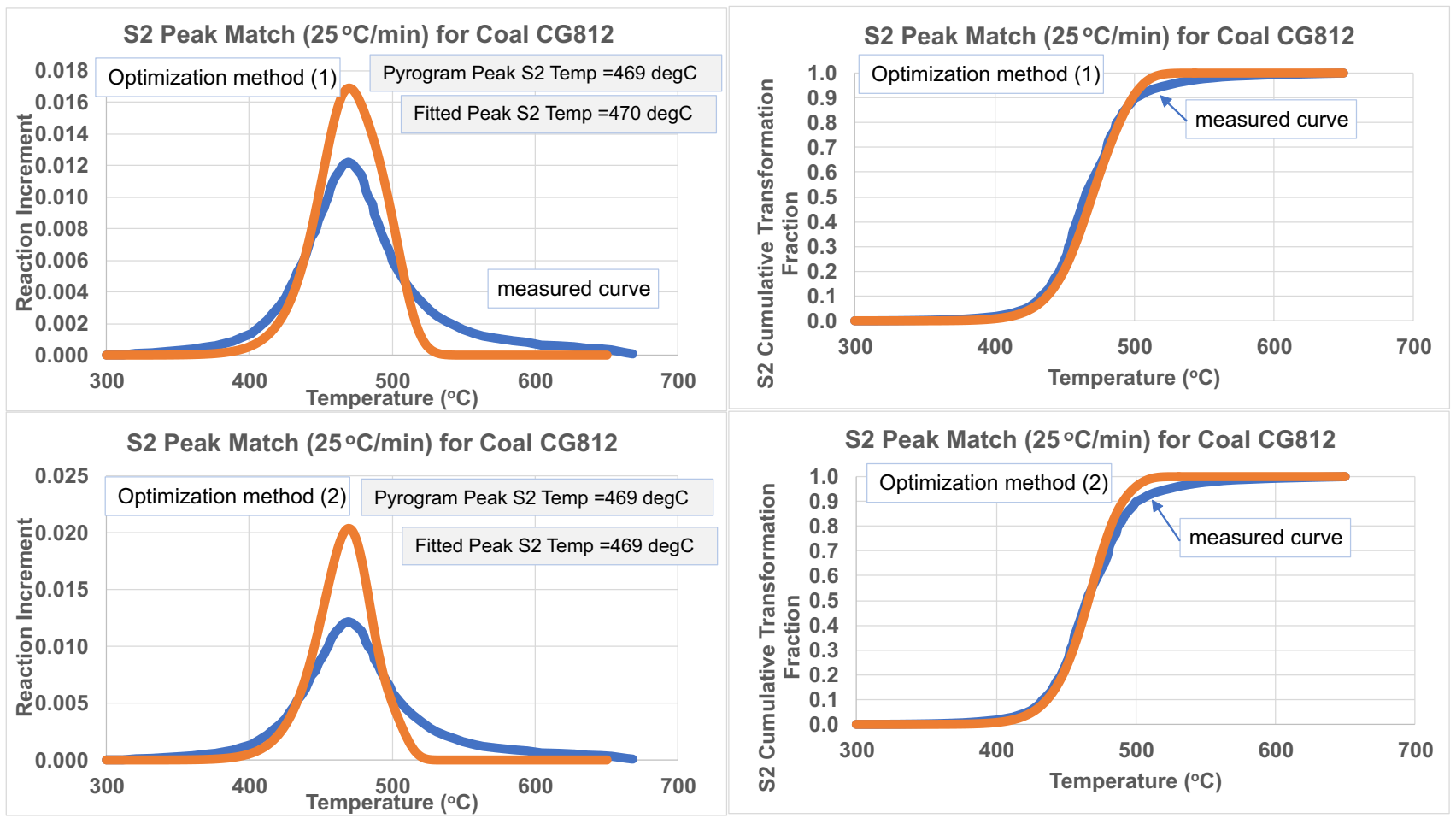

Fig. 9. Measured versus modelled S2 peak for early-mature Raniganj basin coal sample CG $812\left(R_{o}=0.65 \%\right)$ using to different optimization methods (1) upper graphs (2) lower graphs. See text for explanation of kinetic solutions used to derive the modelled curves.

Table 8. Kinetic modelling to achieve fits to S2 peak shapes by applying optimization method (3) followed by optimization method (2) to a mature Raniganj basin shale (CG 1286). The central E-A kinetics $(E=279)$ selected (optimization method (3)) match the S2 peak temperatures at the three heating rates $\left(5^{\circ} \mathrm{C} / \mathrm{min}, 15^{\circ} \mathrm{C} / \mathrm{min}\right.$ and $\left.25^{\circ} \mathrm{C} / \mathrm{min}\right)$ exactly. By building the $\mathrm{E}$ values out in each direction along a single $\mathrm{A}$ value a very good fit to the measured S2 peak is obtained. However, the assumptions associated with this method are probably unrealistic, as discussed in the text.

\begin{tabular}{|c|c|c|c|c|c|c|c|c|}
\hline \multicolumn{9}{|c|}{ Optimized S2 peaks kinetic solutions in terms of E-A contributions } \\
\hline \multirow{3}{*}{ Sample \# } & \multirow{2}{*}{\multicolumn{4}{|c|}{$\begin{array}{l}\text { Optimization methods (3) followed by (2) } \\
\text { applying a "quick" E fit by trical \& error } \\
\text { A located by (3): E then can vary with fixed A }\end{array}$}} & \multicolumn{4}{|c|}{$\begin{array}{l}\text { Optimization methods (3) followed by (2) } \\
\text { applying a fit using the Solver optimizer }\end{array}$} \\
\hline & & & & & \multicolumn{4}{|c|}{ A located by (3): E then can vary with fixed A } \\
\hline & $\begin{array}{l}\text { Fraction } \\
\text { (manual } \\
\text { estimates) }\end{array}$ & $\begin{array}{l}\mathrm{E} \\
(\mathrm{kJ} / \mathrm{mol})\end{array}$ & $\begin{array}{l}\operatorname{LnA} \\
(/ \mathrm{min})\end{array}$ & $\begin{array}{l}\text { LnA } \\
(/ \mathrm{my})\end{array}$ & $\begin{array}{l}\text { Fraction } \\
\text { (manual } \\
\text { estimates) }\end{array}$ & $\begin{array}{l}\mathrm{E} \\
(\mathrm{kJ} / \mathrm{mol})\end{array}$ & $\begin{array}{l}\operatorname{LnA} \\
(/ \mathrm{min})\end{array}$ & $\begin{array}{l}\text { LnA } \\
(/ \mathrm{my})\end{array}$ \\
\hline \multirow{10}{*}{$\begin{array}{l}\text { CG } 1286 \\
\mathrm{R}_{\mathrm{o}}=1.13 \\
\text { shale } \\
\text { "excellent" fit }\end{array}$} & & & & & 0.010 & 225 & 43.94 & 70.93 \\
\hline & 0.050 & 250 & 43.94 & 70.93 & 0.029 & 238 & 43.94 & 70.93 \\
\hline & 0.060 & 260 & 43.94 & 70.93 & 0.039 & 251 & 43.94 & 70.93 \\
\hline & 0.080 & 270 & 43.94 & 70.93 & 0.076 & 264 & 43.94 & 70.93 \\
\hline & 0.400 & 279 & 43.94 & 70.93 & 0.400 & 279 & 43.94 & 70.93 \\
\hline & 0.180 & 290 & 43.94 & 70.93 & 0.202 & 293 & 43.94 & 70.93 \\
\hline & 0.080 & 300 & 43.94 & 70.93 & 0.115 & 306 & 43.94 & 70.93 \\
\hline & 0.050 & 310 & 43.94 & 70.93 & 0.078 & 322 & 43.94 & 70.93 \\
\hline & 0.050 & 320 & 43.94 & 70.93 & 0.051 & 340 & 43.94 & 70.93 \\
\hline & 0.050 & 330 & 43.94 & 70.93 & & & & \\
\hline
\end{tabular}

Opt. 3 locates the central E-A value by allowing both to vary widely and finding the A value that best matches the S2 peak temperatures at three different pyrolysis heating rates. Opt. 2 then builds out in both R directions from the centrally located $\mathrm{E}$ value at fixed A, asymmertrically if necessary to match the measured peak, which has a high right-side shoulder. 


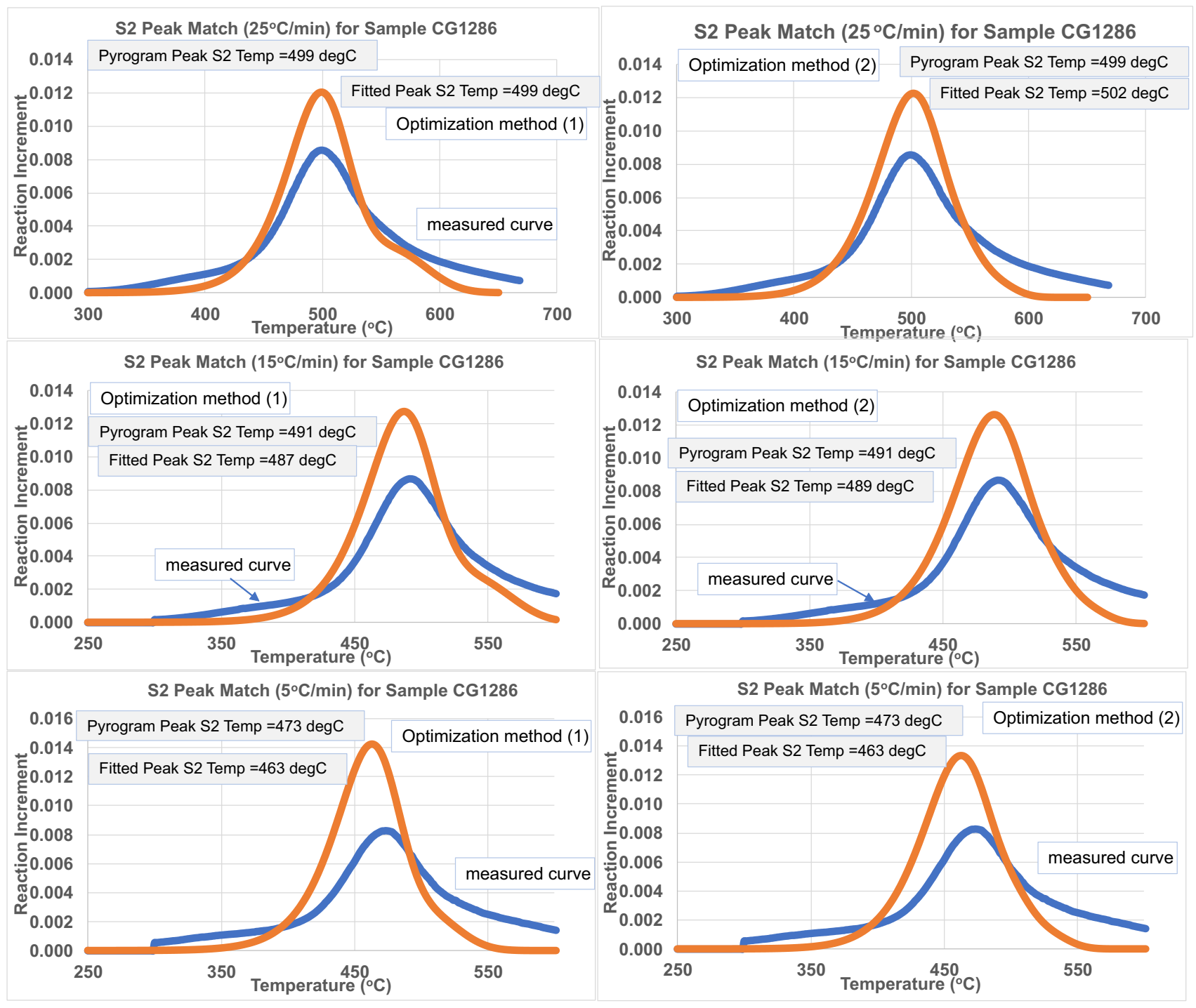

Fig. 10. Measured versus modelled multi-heating rate $\mathrm{S} 2$ peaks for peak-mature Raniganj basin shale sample CG $1286\left(\mathrm{R}_{\mathrm{o}}=1.13 \%\right)$ using to different optimization methods (1) left-side graphs (2) right-side graphs. See Table 6 and the text for explanations of kinetic (E-A) solutions used to derive the modelled curves. Samples CG 1283 and CG 1284 (not shown) show similar fitting results for optimization methods (1) and (2).

(Opt. 2), cannot adequately explain all the characteristics of the S2 peaks of the Raniganj samples; particularly so for the more mature samples.

\subsection{Optimizing S2-peak shape fitting constrained to} $E-A$ values that best match all the multi-heating rate S2-peak temperatures (Opt. 3)

Optimization method (3) (Opt. 3) defining a discrete distribution of $\mathrm{E}$ values for a fixed value of $\mathrm{A}$ is the approach that has used most commonly for almost three decades to derive kerogen activation energy distributions. The initial advocates of this approach (Sundararaman et al., 1992) pointed out that the single-A value used " can lead to erroneous results, especially for organic matter associated with a very broad activation energy distribution, i.e., type III kerogen ", which we believe to be the case. However, mixing of reaction kinetics for the fixed A value that matches the S2 peak temperatures for all the multi-rate heating ramps (i.e., a vertical line in Fig. 7, like Opt. 2) makes it relatively easy to establish fits for S2 peaks of almost any shape. This explains in part why this approach is so widely applied without considering the just how unlikely it is that for source rocks with mixed macerals the S2 peak shapes can be realistically defined by a discrete distribution of $\mathrm{E}$ values locked into a single $\mathrm{A}$ value.

Table 8 shows the results for Opt. 3 applied to peakmature sample CG 1286 that locates the central E-A value that matches precisely the S2 peak temperatures of the threeheating rate pyrograms available for that sample. The Excel Solver optimizer pinpointed this as $\mathrm{E}=280 \mathrm{~kJ} / \mathrm{mol}$ and $\mathrm{LnA}$ $=43.94 / \mathrm{min}$ (or $70.93 / \mathrm{my}$ ). The next step is to build the discrete $\mathrm{E}$ distribution around that central $\mathrm{E}$ value (i.e., a range of $\mathrm{E}$ values increasing from and decreasing from that central 


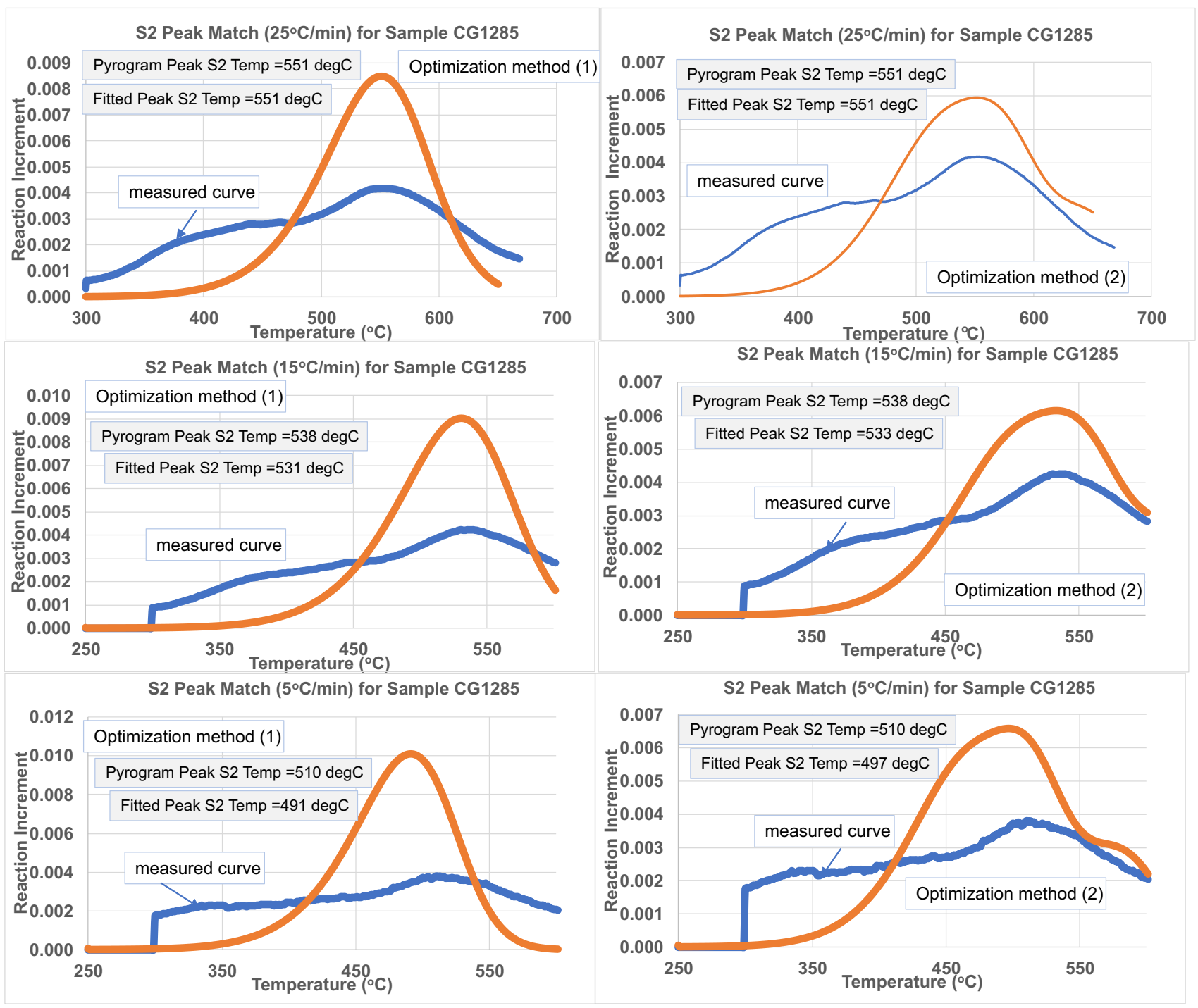

Fig. 11. Measured versus modelled multi-heating rate $S 2$ peaks for post-mature Raniganj basin shale sample CG $1285\left(R_{0}=2.23 \%\right)$ using to different optimization methods (1) left-side graphs (2) right-side graphs. See Table 6 and the text for explanations of kinetic (E-A) solutions used to derive the modelled curves.

E value), all locked into that fixed A value. The results of an initial smoothing adjustment that extrapolate from that central E-value point are shown in Table 8 (left side) and Fig. 12. The right side of Table 8 shows a more precise fit obtained by an optimizer.

Clearly, an almost exact match of the S2 peaks at each heating rate can be readily obtained (even without applying the Opt. 2 optimizer). As the S2 peaks measured for CG 1286 are asymmetrical (i.e., with a high-right side shoulder), in order to match that the distribution of $E$ values needed to achieve a good fit is also asymmetrical (i.e., extending out further towards higher $\mathrm{E}$ values). To balance this asymmetry, the central E point of $280 \mathrm{~kJ} / \mathrm{mol}$ must be moved slightly (E $=279 \mathrm{~kJ} / \mathrm{mol}$, Table 7) to achieve the peak fits shown in Fig. 12.

Good S2-peak fitting Opt. 3 results, not shown, were also obtained for sample CG 1283 (central E = $244 \mathrm{~kJ} / \mathrm{mol}$; LnA =
$38.18 / \mathrm{min}$ or $65.17 / \mathrm{my}$ ), CG 1284 (central $\mathrm{E}=253 \mathrm{~kJ} / \mathrm{mol}$; $\mathrm{LnA}=39.50 / \mathrm{min}$ or $66.49 / \mathrm{my}$ ) and CG 1285 (central $\mathrm{E}=$ $199 \mathrm{~kJ} / \mathrm{mol} ; \mathrm{LnA}=28.87 / \mathrm{min}$ or $55.86 / \mathrm{my}$ ). Note that there is a significant range in the $\mathrm{E}$ and $\mathrm{A}$ values for these 4 samples, consistent with the results of Opt. 1 and Opt. 2. For example, the much lower E-A values determined for the post-mature sample CG 1285 of E close just below 200 compared to the peak-mature samples with E ranging from 240 to 280 . For the three peak mature samples it may not be a coincidence that the two samples (CG 1283 and CG 1284) with higher pyrite contents (Table 4) display the kinetic fits involving lower E values $(E=244$ and $253 \mathrm{~kJ} / \mathrm{mol}$, respectively) than sample CG 1286 with a lower pyrite content $(\mathrm{E}=280 \mathrm{~kJ} / \mathrm{mol})$.

It is clear from a comparison of Figs. 10, 11 and 12 that the S2 peaks fit achieved by methods optimization (3) (followed by Opt. 2) obtain a closer match to the measured data than optimization methods (1) and (2). The results of the 

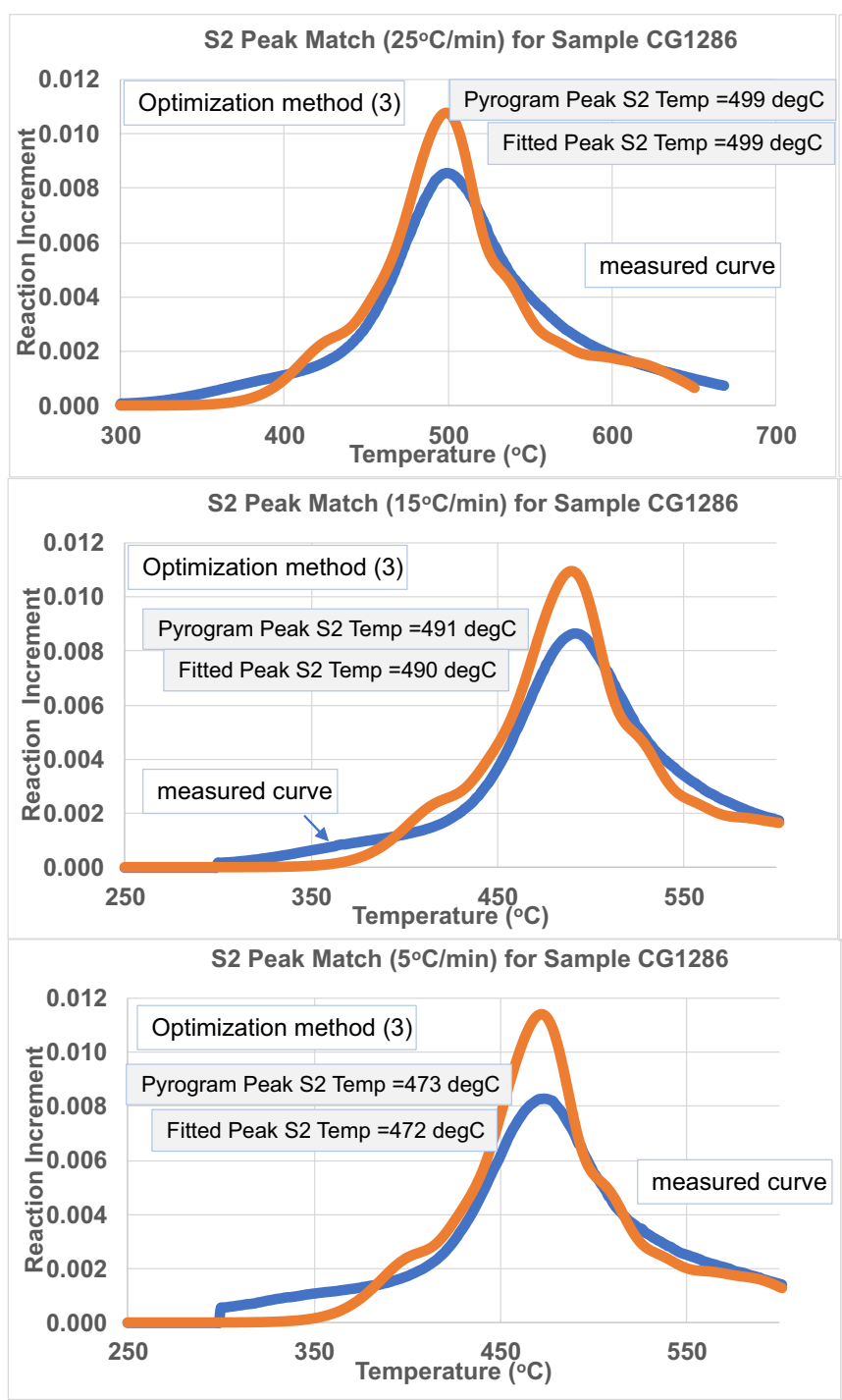

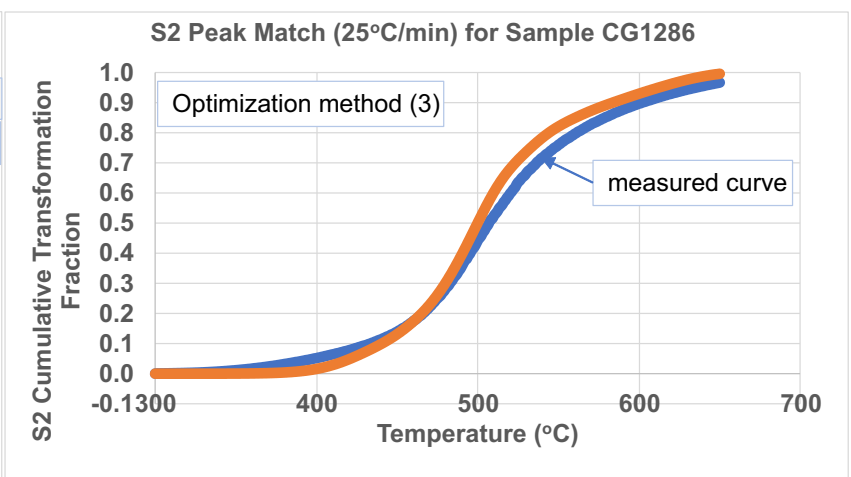

S2 Peak Match $\left(15^{\circ} \mathrm{C} / \mathrm{min}\right)$ for Sample CG1286
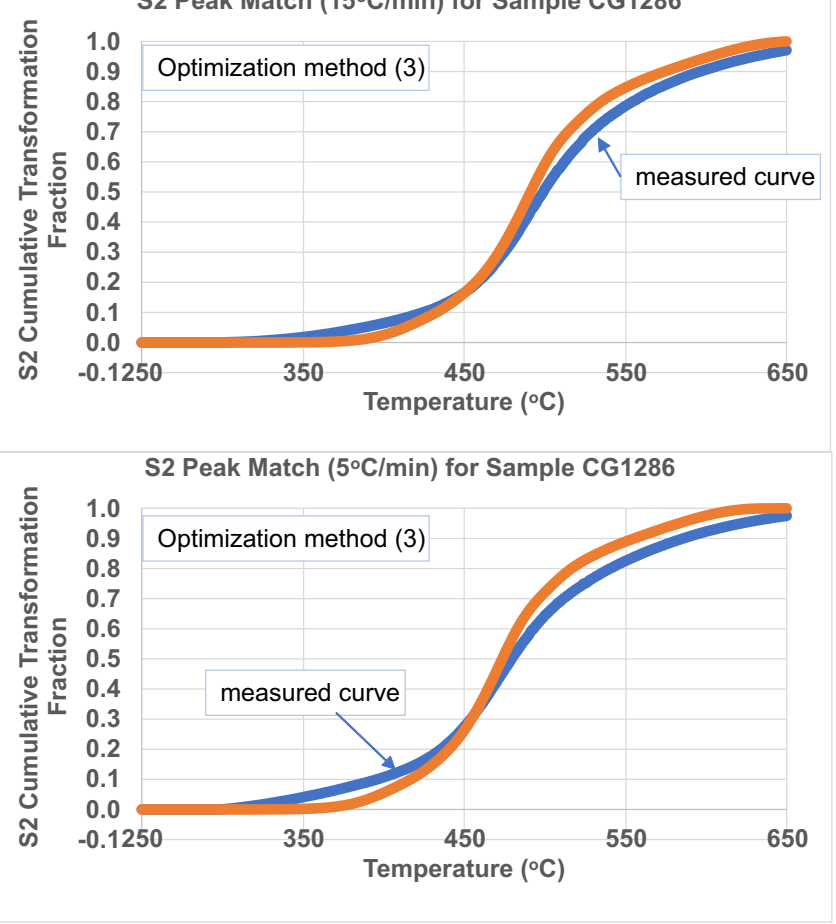

Fig. 12. Measured versus modelled multi-heating rate $\mathrm{S} 2$ peaks for peak-mature Raniganj basin shale sample $\mathrm{CG} 1286\left(\mathrm{R}_{\mathrm{o}}=1.13 \%\right)$ applying optimization method (3) followed by optimization method (2). See Table 7 and the text for explanations of kinetic (E-A) solutions used to derive the modelled curves. This method can achieve very close fits to the multi-rate S2 peaks for samples CG 1283, CG 1284 and CG 1285 (not shown) but with quite distinct E-A values and each involving fixed $\mathrm{A}$ assumptions that are probably not realistic.

E-A kinetic values derived for each sample discussed by each method are summarized in Fig. 13. Two important points are immediately apparent from this graph:

(1) The results of each optimization method suggest that a wide-range of E-A values are in some way associated with the samples studied form the Raniganj basin. This is consistent with their mixed-maceral composition and their wide range of thermal maturity.

(2) The E-A solutions derived from Opt. 3 lie close to the established kerogen kinetic trend (Wood, 1988) even though, unlike the Opt. 1 and Opt. 2 solutions, they are not constrained in a way that forces them to be so.

(3) The Opt. 3 solution for CG 1286 stands out as a vertical line crossing the established kerogen kinetic trend. Even though this discrete E distribution produces the best shape fit to the multi-heating-rate S2 peaks, its applicability as a meaningful E-A distribution with which to model petroleum generation from the Raniganj shales is considered doubtful.

\section{Discussion regarding S2 peak shape analysis and evolution}

The foregoing analysis suggests that meaningful information regarding kerogen kinetics can be obtained by fitting firstorder kinetic models to $\mathrm{S} 2$ pyrogram peaks using the $\sum T T I_{A R R}$ time-temperature integral (Wood, 1988, 2017a) technique to both single-heating-rate and multiple-heating rate data of complex organic-rich rocks (i.e., with mixed macerals and at varying degrees of thermal maturity).

However, obtaining perfect fits to the S2 peak shapes using optimization techniques that incorporate a wide range 


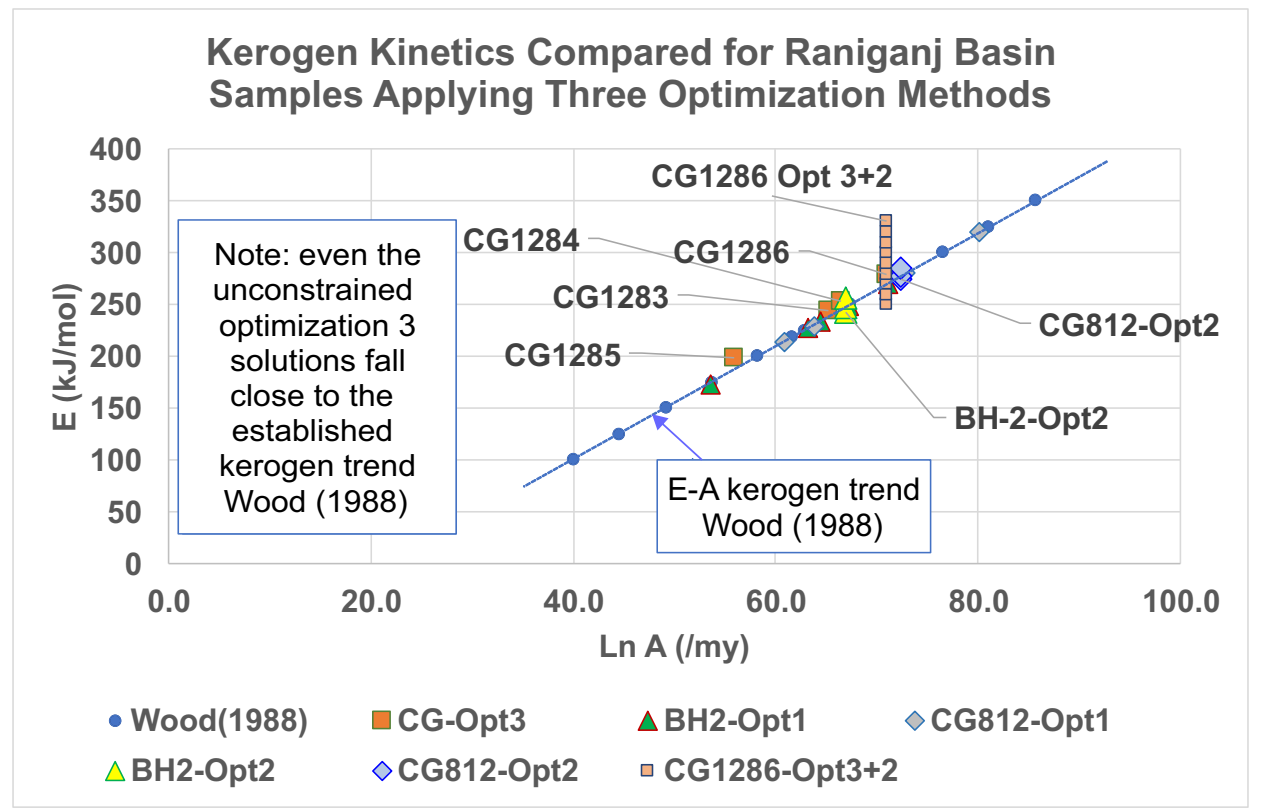

Fig. 13. Summary E-LnA diagram for Raniganj shale and coal kerogen-kinetic results (predicted E-A values, either single or multiple pairs) applying three different optimization approaches. Opt. 1, Opt. 2 and Opt. 3 refer to optimization methods 1,2 and 3 respectively.

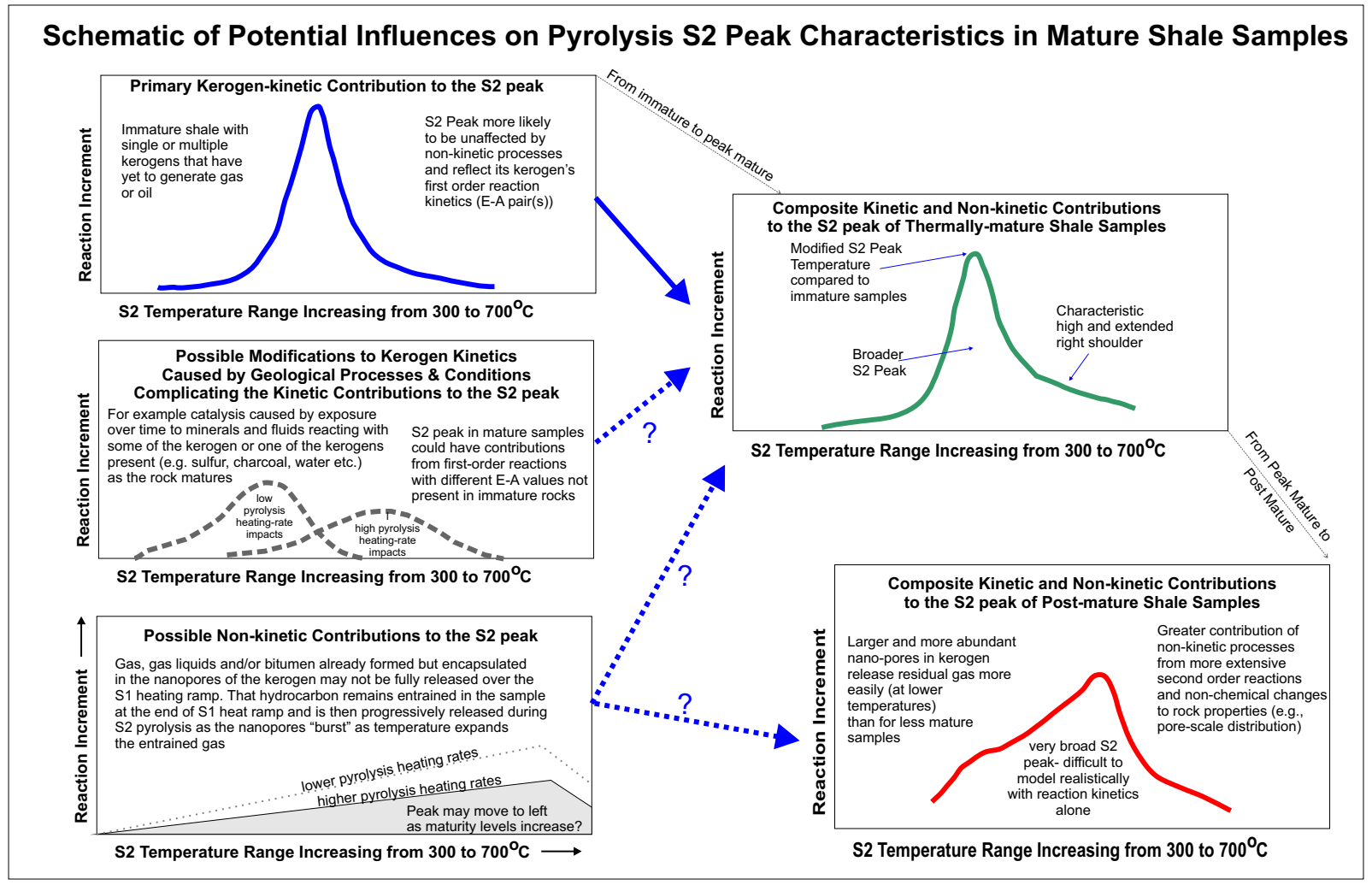

Fig. 14. Concept diagram of how the $S 2$ peak may evolve from an immature to a post-mature sample and some of the potential influences involved. 
of realistic kerogen kinetics (variable $\mathrm{E}$ and A values applied to each sample-optimization methods (Opt. 1 and Opt. 3)) is not easily attainable.

Nevertheless, the E-A values ranges for the fits of the central S2 peaks, by this method are plausible. On the other hand, almost perfect fits to the $\mathrm{S} 2$ peak shapes can be produced by using fixed A values that match the S2 peak temperatures from the different heating ramps, but the $\mathrm{E}$ distribution required to do that are considered to be implausible. Moreover, in all optimization approaches applied, as the level of thermal maturity increases the $\mathrm{E}$ values in the optimum solutions decrease. This is due to the S2 peaks widening and their right-side shoulder (flank) rising (i.e., becoming exaggerated) at peak maturity, followed subsequently by their left-side shoulder becoming exaggerated during post-maturity.

It seems likely that factors other than static first-order reaction kinetics are likely to be at play in determining the S2 peak characteristics of complex shales. Fig. 14 provides a concept diagram of how some of these factors and processes might work in an integrated fashion to determine the evolution of the S2 peak for mixed maceral samples as thermal maturity progresses. The following points are worthy of consideration:

- Thermally immature samples are more likely to have their S2 peaks dominated by first order kinetic reactions. If there is a single kerogen type the S2 peak is likely to be narrow and symmetrical. For mixed-maceral immature samples the S2 peak is likely to be broader and, if the kerogen present have significantly different kinetics the S2 peaks are likely to vary from slightly asymmetrical to in some cases bimodal (or multi-modal shapes). Either the left-flank or the right-flank of the S2 peak can be exaggerated depending upon the exact kinetic relationships between the mixed macerals. In the case of the Raniganj samples the immature samples have a slightly exaggerated right-side shoulder for high-heating rate samples, which probably reflects the contribution of a minor kerogen component with a lower $\mathrm{E}$ value than the dominant kerogen.

- As time passes, the formations become more deeply buried and temperatures rise, it becomes more likely that one or more of the mixed macerals present may have its kinetics impacted by reactions with other components present in the rock (e.g., either degraded in some way or catalytically enhanced). Sulphur contained within kerogen has been reported as a kerogen catalyst (Lewan, 1985) and high temperature formation fluids bringing various metal in direct contact with at least some of the kerogen are also likely to be potential catalysts. In the case of the Raniganj shales two other factors make such modifications to the kerogens likely: 1) large sections of the shales probably reached peak thermal maturity 150 my before present or more (but have subsequently been uplifted); 2) they contain large quantities of inertinite (fossilized charcoal) which may in a similar way that activated acts as a catalyst and catalyst support carbon (Larson and Walton, 1940; Juntgen, 1986; Trogadas et al., 2014).

In mixed-maceral shales it is likely that the different kerogen components will be impacted differently by such reactions. This means that the net effect of their combined first order reactions changes (i.e., as reflected in changes to the S2 peak shapes and S2 peak temperature; see middle-left graph Fig. 14).

- It is now well documented that kerogen-bearing shales have complex microstructures (Yang et al., 2016), and as they progress through stages of thermal maturity their pore size distribution evolves, due to a large extent to the growth of isolated nanopores $(<1 \mathrm{~nm}$ diameter $)$ in their kerogen, along with a spectrum of micropores $(<2$ $\mathrm{nm}$ ) and mesopores (50 nm) (Chalmers et al., 2009, 2012; Clarkson et al. 2013; Wood and Hazra, 2017b). Fig. 15 illustrates the pore size distribution complexity measured by $\mathrm{CO}_{2}$-adsorption analysis (Hazra et al., 2018c) for the thermally mature $\left(\mathrm{R}_{\mathrm{o}}=0.95 \%\right)$ Permian shale sample WB BH-20 from the West Bokaro basins (in the Domador valley close to the Raniganj basin). During the peak stages of thermal maturity this complex distribution of pore sizes fills, or partly fills, with generated petroleum (gas and/or liquids), some of which remains trapped until the pores in the kerogen eventually grow (as thermal maturity progresses), burst and coalesce enabling the petroleum to migrate through, and out of, the kerogen. At certain stages of thermal maturity (e.g., early and peak thermal maturity) a significant portion of the nanopores could possibly remain gas/liquid filled, but in an isolated (non-migratable) state. Subjecting such samples to pyrolysis is likely to lead to complex pyrograms. Much of the petroleum in the isolated nanopores may not be released during the S1-peak heating ramp. However, as temperatures rise through the S2-peak heating ramp then these isolated kerogen nanopores are likely to progressively burst, coalesce and release their already formed petroleum. This is speculation and it requires future detailed experimental studies to confirm or refute this possibility and the processes involved. If such a process is at play then it does not involve first-order kinetic reactions (as those occurred at an earlier stage to generate the petroleum), but the released petroleum will contribute to the S2 peak. If this is how at least some mature samples behave during S2 pyrolysis, then its contribution to the S2 peak is likely to increase in a ramp-like manner as temperature rises (see bottom-left graphic in Fig. 14). At lower pyrolysis heating rates, such gas in trapped nanopores, if confirmed to exist by experiment, may be released at lower temperatures than for fast heating rates, as the isolated nanopores would have more time in each temperature interval to coalesce and release their fluids.

- A recent study ( $\mathrm{Li}$ et al., 2018) focused on Eocene oil-prone shales from the Bohai Basin (China) used solvent extraction experiments to demonstrate that some heavy oil and bitumen were retained and absorbed to the kerogen during the S2 stage of pyrolysis. Moreover, the ultimate release of those adsorbed products influenced the shape of the S2 pyrolysis peaks and peak temperatures. Those results support our contention that some previously generated hydrocarbons may be progressively 


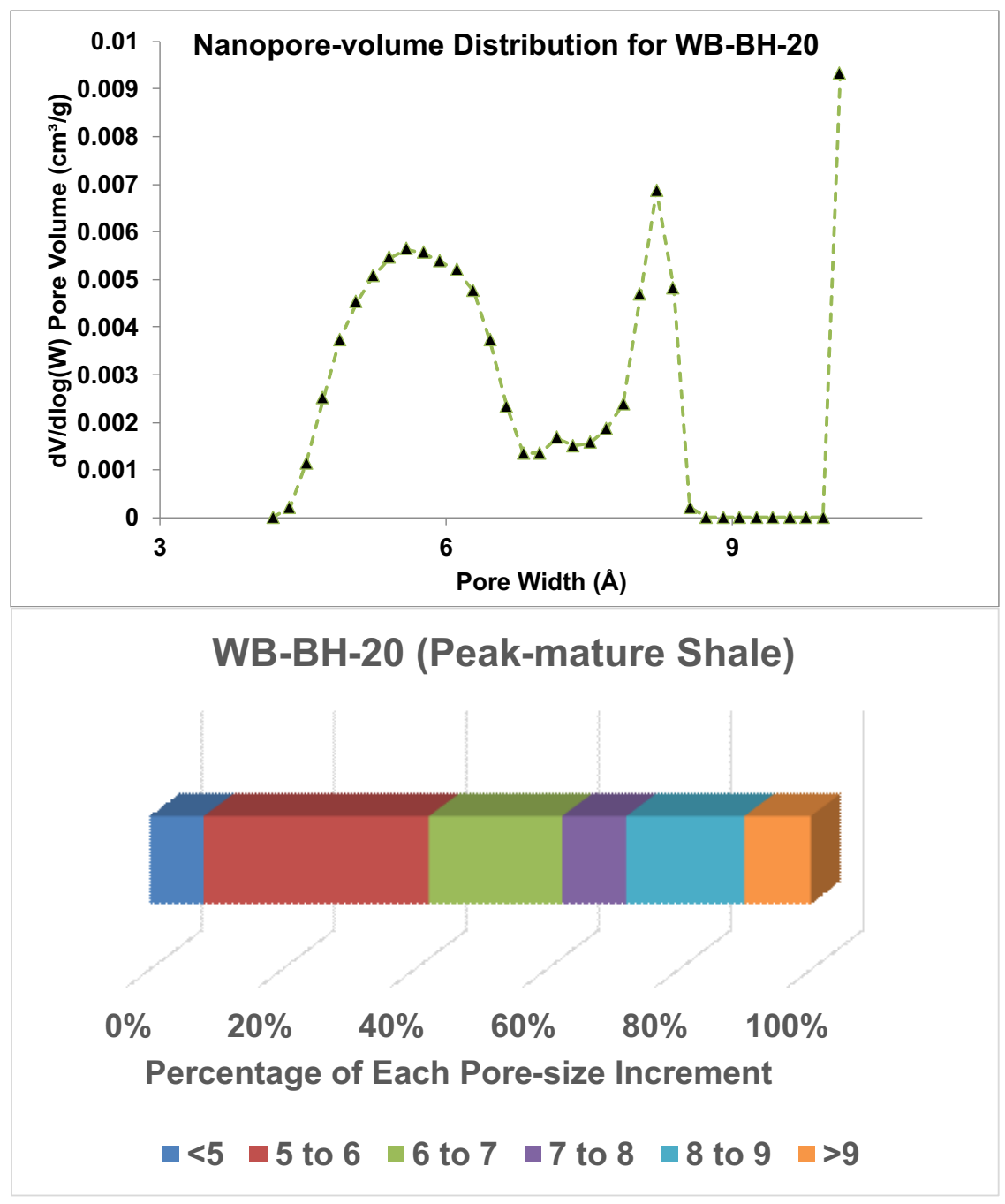

Fig. 15. Pore volume distributions and percentage of each pore size increment compared from $\mathrm{CO}_{2}$-adsorption data for peak-mature (West Bokaro Basin; $\left.\mathrm{R}_{\mathrm{o}}=0.95 \%\right)$ Permian shale sample WB-BH-20 (crushed to 75-212 microns). Upper graph: $\mathrm{dV} / \mathrm{dlog}(\mathrm{W})$ vs pore width $(\AA)$ reveals the bi-modal nanopore volume distribution (where $\mathrm{V}$ is volume and $\mathrm{W}$ is width), as maturity advances in some post-mature shales this distribution changes and becomes multi-modal in some cases (Hazra et al., 2018). Lower graph: percentage of the total pore volume of nanopore size ranges $(<5 ; 5$ to $6 ; 6$ to $7 ; 7$ to $8 ; 8$ to 9 ; and $>9$ Angstroms). Note: 1 Angstrom $=1 / 10 \mathrm{~nm}$ and 1/10000 microns.

released during the pyrolysis S2 heating ramp. Laboratory extraction experiments could help to clarify this, although identifying retained gas would be more difficult than solvent extraction of residual heavy oil/bitumen.

- It is feasible that the S2 peaks of samples at peak-thermal maturity are made up of contributions of all three of these processes (and probably some other unspecified processes), as follows: 1) The first-order kinetic signature is still visible and probably determines the mid-S2 peak shape; 2) the S2 peak temperature may have been shifted by catalytic reactions that impact the kerogen during its burial history; and, 3) the progressive release of petroleum (gas, gas/liquids and/or bitumen) from the isolated nanopores in the kerogen could be responsible for the exaggeration of the right-side S2 peak shoulder (flank). This complex integration of processes building up the S2 peak leads to the asymmetrical shape illustrated in the top right graphic of Fig. 14, which mirrors the S2-peak shapes determined for the peak-mature Raniganj basin samples.

- The complex asymmetrical S2 peak shape with the raised right-shoulder may be a possible exploration tool to identify peak mature shales containing generated gas/liquids held partially trapped in nanopores within their kerogen. This signature S2 shape for peak-mature samples, is potentially made up of a complex integration of firstorder reaction kinetics, kerogen modification processes, and non-kinetic geomechanical constraints imposed by the shale fabric. It seems inconceivable that such a complex S2 signature could be realistically represented by a discrete distribution of activation energies (E) at a constant pre-exponential factor (A).

- As the shales progress through to post-mature conditions, non-kinetic processes may have an even greater significance on their S2 peaks. Moreover, in such shales it is known that nanopores in the kerogen produced as part of the petroleum generation processes firstly became more abundant and more closely spaced and ultimately grow to 
larger micropore diameters. Such a significant change in the pore size distribution of post-mature shales is likely to impact the way in which gas previously generated (by first-order reactions and the cracking of liquids at high temperatures over time) might be released during the S2-stage of pyrolysis. It is considered feasible that gas still trapped in the micropores of the residual kerogen would be released more easily than for the peak mature shales, i.e., at lower temperatures on the $\mathrm{S} 2$ heating ramp. The peak on the schematic pore-gas release curve shown in the lower left graph of Fig. 14 would be displaced substantially to the left. This would lead to an S2 shape with a significantly raised left shoulder and an S2 peak shifted further to the right, as illustrated by the lower right graphic in Fig. 14. Note that the post-mature Raniganj basin shale samples (BH-16 and CG 1285) display this signature. If the S2 peaks originated in the way described for post-mature shales it would be unrealistic to expect to match them precisely with first-order kinetic reactions alone.

- Fig. 14 supports the generally accepted rule that to meaningfully quantify the kerogen kinetics of shales it is better to use thermally immature samples for multi-ramp pyrolysis tests. However, it does not follow that useful information cannot be extracted from pyrolysis tests on thermally mature samples or those tests that involve just a single heating rate. These more complex S2 shapes may be more difficult to model and match precisely, but useful insight can be gained regarding kerogen kinetics and the potential of such samples to release their petroleum.

- If all or part of the speculative processes described in schematic terms in Fig. 14 are involved in the thermal evolution of organic-rich shales, applying only first-order reaction kinetics with a discrete $\mathrm{E}$ distribution and fixed A component to model them is unrealistic, even if good fits to the peak shapes can be manipulated by such a technique.

\section{Conclusions}

Detailed analysis of the shape characteristics of the S2 pyrolysis peak for selected Permian shale and coal samples from the Raniganj basin (India) of various levels of thermal maturity provide significant insight to the evolution of kerogen kinetics and possible other processes involved in petroleum generation and release associated with this gas-prone basin. Mineralogical analysis reveals that these shales are made up of mixed macerals (mainly vitrinite and inertinite with minor but significant quantities of liptinite) and with a significant pyrite component.

Kinetic modelling using the $\sum T T I_{A R R}$ time-temperature integral method is able to model the S2 peak shapes of these samples to varying degrees of precision with the aid of three distinct optimization methods: Opt. 1) with kinetic metrics (E and A) constrained to a well-establish kerogen kinetic trend; Opt. 2) with a fixed pre-exponential factor (A) located on that established kerogen trend; Opt. 3) with EA initially unconstrained but locating a single optimum E-A value that matches the S2 peak temperatures of multi-heating rate pyrograms, followed by generating an $\mathrm{E}$ distribution at that fixed A value.

As the samples become more thermally mature, their S2 peak peaks broaden and their right-side flank becomes exaggerated at peak thermal maturity. Subsequently, their leftside flank becomes exaggerated in samples that reach postthermal maturity levels. These characteristics cannot be easily matched by static first-order kerogen kinetics alone. Such characteristic S2-peak shapes have the potential to be useful shale gas exploration tools as they can identify those shale zones containing generated gas some of which may remain in at least part of the kerogen porosity distribution.

Data analysis suggests that first-order kerogen kinetic reactions appear to be dominating the S2 peak formation and the kinetics of those reactions can be revealed by analyzing the shape of the S2 peaks. However, a speculative case is made to explain some of the distinctive S2-peak shape changes as thermal maturity progresses in terms of processes that are distinctly not simple first-order reactions, including: 1 ) the progressive release of previously-generated gas, gas liquids and/or bitumen held in isolated nanopores within the kerogen across the S2 heating ramp; and 2) acceleration of kerogen reaction rates caused by catalytic processes. For the Raniganj basin samples studied, the peak-mature samples indicate kerogen kinetics involving contributions from lower activation energies than thermally-immature samples. These generally faster first order reactions may have been caused by catalytic effects of sulfur and charcoal (inertinite) present in these rocks reacting with the kerogen over the 150 my or so since these shales initially reached peak thermal maturity.

\section{Acknowledgments}

The Director, CSIR-CIMFR Dhanbad is thanked for providing the necessary infrastructure to conduct the sample collection and analysis. Prof. Suryendu Dutta and Mr. Sumit Kumar from the Department of Earth Sciences, IIT Bombay are thanked for conducting the Rock-Eval analysis on samples BH-1 to BH-20. The Director CSIR-National Geophysical Research Institute and Dr Devleena Mani are thanked for their help in conducting the Rock-Eval analysis for samples CG 1283-CG 1286.

Open Access This article is distributed under the terms and conditions of the Creative Commons Attribution (CC BY-NC-ND) license, which permits unrestricted use, distribution, and reproduction in any medium, provided the original work is properly cited.

\section{References}

Arrhenius, S. Über die Reaktionsgeschwindigkeit bei der Inversion von Rohrzucker durch Säuren. Z. Phys. Chem. 1889, 4(1): 226-248.

Behar, F., Beaumont, V., De B. Penteado, H.L. Rock-Eval 6 technology: Performances and developments. Oil Gas Sci. Technol. 2001, 56(2): 111-134.

Boruah, A., Ganapathi, S. Microstructure and pore system analysis of Barren Measures shale of Raniganj field, India. J. Nat. Gas Sci. Eng. 2015a, 26: 427-437. 
Boruah, A., Ganapathi, S. Organic richness and gas generation potential of Permian Barren Measures from Raniganj field, West Bengal, India. J. Earth Syst. Sci. 2015b, 124(5): 1063-1074.

Carvajal-Ortiz, H., Gentzis, T. Critical considerations when assessing hydrocarbon plays using Rock-Eval pyrolysis and organic petrology data: Data quality revisited. Int. J. Coal Geol. 2015, 152: 113-122.

Casshyap, S.M., Tewari, R.C. Depositional model and tectonic evolution of Gondwana Basins. Palaeobtanist 1987, 36: 59-66.

Chalmers, G., Bustin, R.M., Power, I. A pore by any other name would be as small: The importance of meso-and microporosity in shale gas capacity. Paper Presented at the AAPG Annual Convention and Exhibition, Denver, Colorado, USA, June, 2009.

Chalmers, G.R., Bustin, R.M., Power, I.M. Characterization of gas shale pore systems by porosimetry, pycnometry, surface area, and field emission scanning electron microscopy/transmission electron microscopy image analyses: Examples from the Barnett, Woodford, Haynesville, Marcellus, and Doig units. AAPG Bull. 2012, 96(6): 1099-1119.

Chen, Z., Jiang, C., Lavoie, D., et al. Model-assisted RockEval data interpretation for source rock evaluation: Examples from producing and potential shale gas resource plays. Int. J. Coal Geol. 2016, 165: 290-302.

Chen, Z., Liu, X., Guo, Q., et al. Inversion of source rock hydrocarbon generation kinetics from Rock-Eval data. Fuel 2017, 194: 91-101.

Clarkson, C.R., Solano, N., Bustin, R.M., et al. Pore structure characterization of North American shale gas reservoirs using USANS/SANS, gas adsorption, and mercury intrusion. Fuel 2013, 103: 606-616.

EIA. Energy Information Administration/Annual Energy Review 2011. USA, Government Printing Office, 2012.

Espitalié, J., Madec, M., Tissot, B. Role of mineral matter in kerogen pyrolysis: Influence on petroleum generation and migration. AAPG Bull. 1980, 64(1): 59-66.

Hazra, B., Dutta, S., Kumar, S. TOC calculation of organic matter rich sediments using Rock-Eval pyrolysis: Critical consideration and insights. Int. J. Coal Geol. 2017, 169: 106-115.

Hazra, B., Varma, A.K., Bandopadhyay, A.K., et al. Petrographic insights of organic matter conversion of Raniganj basin shales, India. Int. J. Coal Geol. 2015, 150: 193-209.

Hazra, B., Varma, A.K., Bandopadhyay, A.K., et al. FTIR, XRF, XRD and SEM characteristics of Permian shales, India. J. Nat. Gas Sci. Eng. 2016, 32(3): 239-255.

Hazra, B., Wood, D.A., Varma, A.K., et al. Insights into the effects of matrix retention and inert carbon on the petroleum generation potential of Indian Gondwana shales. Mar. Pet. Geol. 2018a, 91: 125-138.

Hazra, B., Wood, D.A., Vishal, V., et al. Porosity controls and fractal disposition of organic-rich Permian shales using low-pressure adsorption techniques. Fuel 2018b, 220: 837-848.
Hazra, B., Wood, D.A., Vishal, V., et al. Pore-characteristics of distinct thermally mature shales: influence of particle sizes on low pressure $\mathrm{CO}_{2}$ and $\mathrm{N}_{2}$ adsorption. Energy Fuels 2018c.

Jarvie, D.M. Shale resource systems for oil and gas: Part 1: Shalegas resource systems. AAPG Memoir 2012a, 97: 69-87.

Jarvie, D.M. Shale resource systems for oil and gas: Part 2: Shale-oil resource systems. AAPG Memoir 2012b, 97: 89-119.

Juntgen, H. Activated carbon as a catalyst support: A review of new research results. Fuel 1986, 65(10): 1436-1446.

Lafargue, E., Espitalie, J., Marquis, F., et al. Rock-Eval 6 applications in hydrocarbon exploration, production and soil contamination studies. Oil Gas Sci. Technol. 2006, 53(4): 421-437.

Larson, E.C., Walton, J.H. Activated carbon as a catalyst in certain oxidation-reduction reactions. J. Phys. Chem. 1940, 44(1): 70-85.

Lerche, I., Yarzab, R.F., Kendall, C.G.S.C. Determination of paleoheat flux from vitrinite reflectance data. AAPG Bull. 1984, 68(11): 1704-1717.

Lewan, M.D. Evaluation of petroleum generation by hydrous phrolysis experimentation. Phil. Trans. R. Soc. Lond. A 1985, 315(1531): 123-134.

Lewan, M.D., Ruble, T.E. Comparison of petroleum generation kinetics by isothermal hydrous and nonisothermal opensystem pyrolysis. Org. Geochem. 2002, 33(12): 14571475.

Li, M., Chen, Z., Ma, X., et al. A numerical method for calculating total oil yield using a single routine RockEval program: A case study of the Eocene Shahejie Formation in Dongying Depression, Bohai Bay Basin, China. Int. J. Coal Geol. 2018, 191: 49-65.

Mani, D., Patil, D.J., Dayal, A.M., et al. Gas potential of Proterozoic and Phanerozoic shales from the NW Himalaya, India: Inferences from pyrolysis. Int. J. Coal Geol. 2014, 128: 81-95.

Mendhe, V.A., Mishra, S., Varma, A.K., et al. Gas reservoir characteristics of the lower gondwana shales in Raniganj basin of eastern India. J. Pet. Sci. Eng. 2017, 149: 649664.

Mendhe, V.A., Mishra, S., Varma, A.K., et al. Geochemical and petrophysical characteristics of Permian shale gas reservoirs of Raniganj basin, West Bengal, India. Int. J. Coal Geol. 2018, 188: 1-24.

Mukhopadhyay, G., Mukhopadhyay, S.K., Roychowdhury, M., et al. Stratigraphic correlation between different Gondwana basins of India. J. Geol. Soc. India 2010, 76(3): 251-266.

Passey, Q.R., Bohacs, K.M., Esch, W.L., et al. From oil-prone source rock to gas-producing shale reservoir-geologic and petrophysical characterization of unconventional shale gas reservoirs. Paper SPE 131350 Present at the International Oil and Gas Conference and Exhibition, Beijing, China, 8-10 June, 2010.

Patel, R.C., Sinha, H.N., Kumar, B.A., et al. Basin provenance and post-depositional thermal history along the continen- 
tal P/T boundary of the Raniganj basin, eastern India: Constraints from apatite fission track dating. J. Geol. Soc. India 2014, 83(4): 403-413.

Peters, K.E., Burnham, A.K., Walters, C.C. Petroleum generation kinetics: Single versus multiple heating-ramp open-system pyrolysis. AAPG Bull. 2015, 99(4): 591616.

Peters, K.E., Cassa, M.R. Applied source rock geochemistry: Chapter 5: Part II. Essential Elements 1994, 77: 93-120.

Robinson, P.L. The Indian Gondwana formations-a review. 1st International Symosium on Gondwana Stratgraphy 1970, 201-268.

Sain, K., Rai, M., Sen, M.K. A review on shale gas prospect in Indian sedimentary basins. J. Indian Geophys. Union 2014, 18(2): 183-194.

Srivastava, R.K., Rao, N.V.C., Sinha, A.K. Cretaceous potassic intrusives with affinities to aillikites from Jharia area: Magmatic expression of metasomatically veined and thinned lithospheric mantle beneath Singhbhum Craton, Eastern India. Lithos 2009, 112: 407-418.

Stainforth, J.G. Practical kinetic modeling of petroleum generation and expulsion. Mar. Pet. Geol. 2009, 26(4): 552-572.

Sundararaman, P., Merz, P.H., Mann, R.G. Determination of kerogen activation energy distribution. Energy Fuels 1992, 6(6): 793-803.

Tewari, A., Dutta, S., Sarkar, T. Organic geochemical characterization and shale gas potential of the Permian Barren measures formation, west Bokaro sub-basin, eastern India. J. Pet. Geol. 2016, 39(1): 49-60.

Tissot, B.P., Espitalié, J. L'evolution thermique de la matiere organique des sediments: Applications d'une simulation mathématique. Rev. Inst. Fr. Pet. 1975, 30(5): 743-778.

Tissot, B.P., Welte, D.H. Petroleum formation and occurrence: New York, Springer-Verlag. Earth-Sci. Rev. 1980, 16(16): 372-373.

Trogadas, P., Fuller, T.F., Strasser, P. Carbon as catalyst and support for electrochemical energy conversion. Carbon 2014, 75: 5-42.

Ungerer, P. State of the art of research in kinetic modelling of oil formation and expulsion. Org. Geochem. 1990, 16(1-3): 1-25.

Varma, A.K., Hazra, B., Chinara, I., et al. Assessment of organic richness and hydrocarbon generation potential of Raniganj basin shales, West Bengal, India. Mar. Pet. Geol. 2015a, 59: 480-490.

Varma, A.K., Hazra, B., Samad, S.K., et al. Methane sorption dynamics and hydrocarbon generation of shale samples from West Bokaro and Raniganj basins, India. J. Nat.
Gas Sci. Eng. 2014a, 21: 1138-1147.

Varma, A.K., Hazra, B., Samad, S.K., et al. Shale gas potential of Lower Permian Shales from Raniganj and West Bokaro Basins. India. Paper Presented at the 66th Annual Meeting and Symposium of The International Committee for Coal and Organic Petrology, 2014b.

Varma, A.K., Hazra, B., Srivastava, A. Estimation of total organic carbon in shales through color manifestations. J. Nat. Gas Sci. Eng. 2014c, 18: 53-57.

Varma, A.K., Hazra, B., Srivastava, A. Corrigendum to "Estimation of total organic carbon in shales through color manifestations" [J. Nat. Gas Sci. Eng. 2014, 18: 53-57.] J. Nat. Gas Sci. Eng. 2014d, 20: 1.

Varma, A.K., Khatun, M., Mendhe, V.A., et al. Petrographic characterization and langmuir volume of shales from Raniganj coal basin, India. J. Geol. Soc. India 2015b, 86(3): 283-294.

Veevers, J.J., Tewari, R.C. Gondwana Master Basin of Peninsular India Between Tethys and the Interior of the Gondwanaland Province of Pangea. USA, Geological Society of America, 1995.

Waples, D.W. Petroleum generation kinetics: Single versus multiple heating-ramp open-system pyrolysis: Discussion. AAPG Bull. 2016, 100(4): 683-689.

Wood, D.A. Relationships between thermal maturity indices of arrhenius and lopatin methods: Implications for petroleum exploration. AAPG Bull. 1988, 72(2): 115134.

Wood, D.A. Re-establishing the merits of thermal maturity and petroleum generation multi-dimensional modelling with an arrhenius equation Using a single activation energy. J. Earth Sci. 2017, 28(5): 804-834.

Wood, D.A. Kerogen conversion and thermal maturity modelling of petroleum generation: Integrated analysis applying relevant kerogen kinetics. Mar. Pet. Geol. 2018a, 89: 313-329.

Wood, D.A. Thermal maturity and burial history modelling of shale is enhanced by use of Arrhenius time-temperature index and memetic optimizer. Petroleum 2018b, 4(1): $25-42$.

Wood, D.A., Hazra, B. Characterization of organic-rich shales for petroleum exploration \& exploitation: A reviewpart 1: Bulk properties, multi-scale geometry and gas adsorption. J. Earth Sci. 2017a, 28(5): 739-757.

Wood, D.A., Hazra, B. Characterization of organic-rich shales for petroleum exploration \& exploitation: A reviewpart 2: Geochemistry, thermal maturity, isotopes and biomarkers. J. Earth Sci. 2017b, 28(5): 758-778. 